This article may be downloaded for personal use only. Any other use requires prior permission of the author and AIP Publishing. This article appeared in K. Klinar, A. Kitanovski, Thermal control elements for caloric energy conversion. Renew. Sustain. Energy Rev. 118, 109571 (2020) and may be found at https://www.sciencedirect.com/science/article/abs/pii/S1364032119307798?via\%3Dihub

\title{
Thermal control elements for caloric energy conversion
}

\author{
Klinar, K. ${ }^{1}$, Kitanovski A. ${ }^{1 *}$ \\ $1=$ University of Ljubljana, Faculty of Mechanical Engineering, Askerceva c. 6, 1000 Ljubljana, Slovenia \\ *=Corresponding author: andrej.kitanovski@fs.uni-lj.si
}

\begin{abstract}
Caloric energy conversion is an emerging field of cooling, heat-pumping and power-generation technologies. The potentially high energy efficiency and use of environmentally friendly and safe solid-state working substances in the form of refrigerants has stimulated increased research activity in the past two decades. Most of today's caloric devices apply so-called active regeneration, which involves the oscillation of the working fluid through the matrix of the caloric material - the caloric regenerator. However, the unavoidable, irreversible viscous and heat-transfer losses apply limits to the caloric device's performance as well as its size. The quest for better caloric-device performance has led to the development of thermal control elements, which control the heat flux on different size and time scales. In this paper we describe the working principles of these elements: thermal switches, thermal diodes and thermal regulators. This is followed by the first up-to-date critical review of the research activities and applications of thermal control elements in all types of caloric devices. We show that thermal control elements have the potential to improve the power density of caloric devices. Finally, we propose target features for these elements with respect to future research activities in the field of caloric technologies.
\end{abstract}

\section{Highlights:}

- The operating principles of thermal control elements are described

- The applications of thermal control elements in caloric technologies are explained

- A generalized figure of merit is proposed for different thermal control elements

- Future research guidelines for thermal control elements in calorics are proposed 
Keywords: heat transfer; thermal switch; thermal diode; thermal rectification; energy conversion; magnetocaloric; electrocaloric; elastocaloric

Word count: 8512

\section{Nomenclature}

\begin{tabular}{ccc}
\multicolumn{3}{c}{ Standard } \\
\hline$B$ & $T$ & magnetic field \\
$E$ & $V / m$ & electric field \\
$F$ & $N$ & force \\
$p$ & $P a$ & pressure \\
$\dot{q}$ & $W / m^{2}$ & specific heat flux \\
$r$ & $/$ & switching ratio \\
$R$ & $K / W$ & thermal resistance \\
$T$ & $K$ & temperature
\end{tabular}

\begin{tabular}{ccc}
\multicolumn{3}{c}{ Greek } \\
$\mathcal{H}$ & $/$ & combined figure of merit \\
\multicolumn{3}{c}{ Abbreviations } \\
\hline AMR & active magnetic regenerator \\
$f w d$ & time response \\
mcm & magnetocaloric material \\
rev & reverse
\end{tabular}

\begin{tabular}{cc} 
& Subscripts \\
\hline ad & adiabatic temperature change \\
diode & thermal diode \\
fwd & forward \\
mcm & magnetocaloric material \\
off & off state \\
on & on state \\
regulator & thermal regulator \\
rev & reverse \\
switch & thermal switch
\end{tabular}

\section{Introduction}

The majority of devices or systems in residential and commercial situations used for refrigeration, heat pumping and HVAC make use of vapour-compression technology, which currently has an $80 \%$ market share [1]. More than a hundred years of developments in vapour-compression devices have led to what we are witnessing today: low production and maintenance costs, safe and reliable operation, and the ability to provide cooling in different capacity ranges and temperature spans.

Today, devices of all kinds are being looked at in terms of their impact on the environment and overall energy efficiency. With vapour-compression technologies the energy efficiency is restricted by the irreversible compression and expansion of the refrigerant, and there are additional irreversible losses associated with elements in the device that cannot be neglected [2]. Another weak point of vapour-compression systems is the use of restricted refrigerants that could impact on the environment, with possible replacements frequently offering a reduced energy efficiency and the potential for toxicity, flammability and explosivity $[3,4]$. It is these problems that have stimulated interest in alternative refrigeration and heat-pump technologies.

Important alternatives to vapour compression are adsorption and absorption refrigeration, due to their low electrical power consumption, These two technologies are especially interesting when waste [5-8] or renewable [9-11] heat is available. Similarly, as in sorption refrigeration or heat pump systems, ejector refrigeration systems also perform work without moving parts. Besides the low initial costs and low maintenance, compared to vapour compression, the ejector devices can, similar to sorption refrigeration, utilize low-temperature thermal resources $[12,13]$.

With regards to the electrically driven refrigeration or heat pump systems, another market-available alternative to vapour compression is thermoelectric cooling, which exploits the Peltier effect. However, it suffers from a very low energy efficiency that restricts its use to specific market niches [14,15]. 
Among the remaining alternative technologies, which are still in the $R \& D$ phase, the most promising alternatives to vapour compression are the caloric technologies, especially magnetocalorics [16-18]. The main benefits of caloric technologies over vapour compression are related to the use of environmentally friendly and safe, solid-state refrigerants, a higher energy efficiency compared to irreversible compression and expansion, less noise and a low level of vibrations [19]. As a result, we have witnessed a substantial increase in research activity over the past two decades in magnetocalorics [19-21], electrocalorics [22-25] and elastocalorics [26,27].

Compared to vapour compression, the major drawback of all the caloric technologies is their rather low power density and related costs. Additional drawbacks in existing prototype devices are associated with the need for a high magnetic field (in magnetocalorics), electric field (in electrocalorics) or force (in elastocalorics. Other problems with these new technologies are related to the caloric materials (i.e., the hysteresis, cyclic stability, specific cooling power, adiabatic temperature change) and their processing. And one of the major problems is the efficient and rapid heat transfer required for both, the high power density and the high energy efficiency. Namely, despite the potentially very high energy efficiency, the caloric refrigeration and heat pump prototype devices at present cannot compete with the mature vapour-compression refrigeration. Therefore, very large efforts are being invested in improving the important obstacles by introducing new concepts, which is also the subject of this review paper and the related future guidelines. The comparison of the advantages and drawbacks, which was outlined above, is shown in Table 1 for each particular caloric technology at its present stage of development. Using this we are also pointing out the main directions towards future improvements.

Table 1: Comparison of the main caloric technologies, which is based on existing developments, where the scoring follows the advantages ( + ) and disadvantages (-) on a scale between a very good solution (defined by +++ ) and problems without an evident solution, (defined by ---).

\begin{tabular}{|c|c|c|c|c|}
\hline \multirow{2}{*}{ Characteristics } & \multicolumn{2}{|c|}{ Magnetocalorics } & \multirow{2}{*}{ Electrocalorics } & \multirow{2}{*}{ Elastocalorics } \\
\hline & permanent magnet & electromagnet & & \\
\hline Potential second-law efficiency & +++ & +++ & +++ & +++ \\
\hline Power density per mass of caloric material & - & - & - & - \\
\hline Max. adiabatic temperature change & + & + & - & ++ \\
\hline Cyclic stability of materials & ++ & ++ & -- & -- \\
\hline Silent operation & + & +++ & +++ & -- \\
\hline Low level of vibrations & -- & + & +++ & --- \\
\hline Small or no hysteresis in caloric materials & ++ & ++ & + & - \\
\hline No moving parts needed for operation & --- & +++ & +++ & --- \\
\hline Mechanical movement & --- & +++ & +++ & --- \\
\hline $\begin{array}{l}\text { Losses caused by electric current } \\
\text { (Joule heating, eddy currents) }\end{array}$ & ---- & --- & --- & + \\
\hline Rare-earth caloric materials & + & + & +++ & +++ \\
\hline Rare-earth material in magnetic field source & -- & +++ & +++ & +++ \\
\hline Technology readiness (toward market applications) & + & + & -- & -- \\
\hline
\end{tabular}

Caloric technologies are based on the exploitation of the caloric effect in specific materials. By introducing a change in the magnetic (magnetocaloric effect), electric (electrocaloric effect), stress (elastocaloric effect) or pressure (barocaloric effect) field under adiabatic conditions, the temperature in the caloric material changes. The application of the relevant field increases the temperature of the caloric material, while the removal of the field decreases the temperature. In order to take advantage of the caloric effect, caloric devices operate periodically, as presented in Fig. 1. The heat transfer process follows the periodic change of an externally applied field under adiabatic conditions, from the caloric material to the heat sink or from the heat source to the caloric material (isofield cooling of a caloric material - analogous to condensation, isofield heating of a caloric material - analogous to evaporation). Each caloric thermodynamic cycle therefore consists of four processes and the number of completed thermodynamic cycles in a unit of time denotes the operating frequency. 
Because the maximum adiabatic temperature change due to the caloric effect is smaller than the required temperature span for use in refrigeration, regenerative heat-exchange methods are applied, similar to other cooling technologies [28]. The majority of caloric devices developed so far apply an active caloric regenerator, as first reported by Barclay and Steyert in 1981 [29] for the case of magnetocaloric cooling. An active caloric regenerator consists of a porous, solid matrix of the caloric material and enables the heat to be regenerated with a working fluid. The oscillatory flow of the heat-transfer fluid through the active caloric regenerator is coupled with a change in the externally applied field.

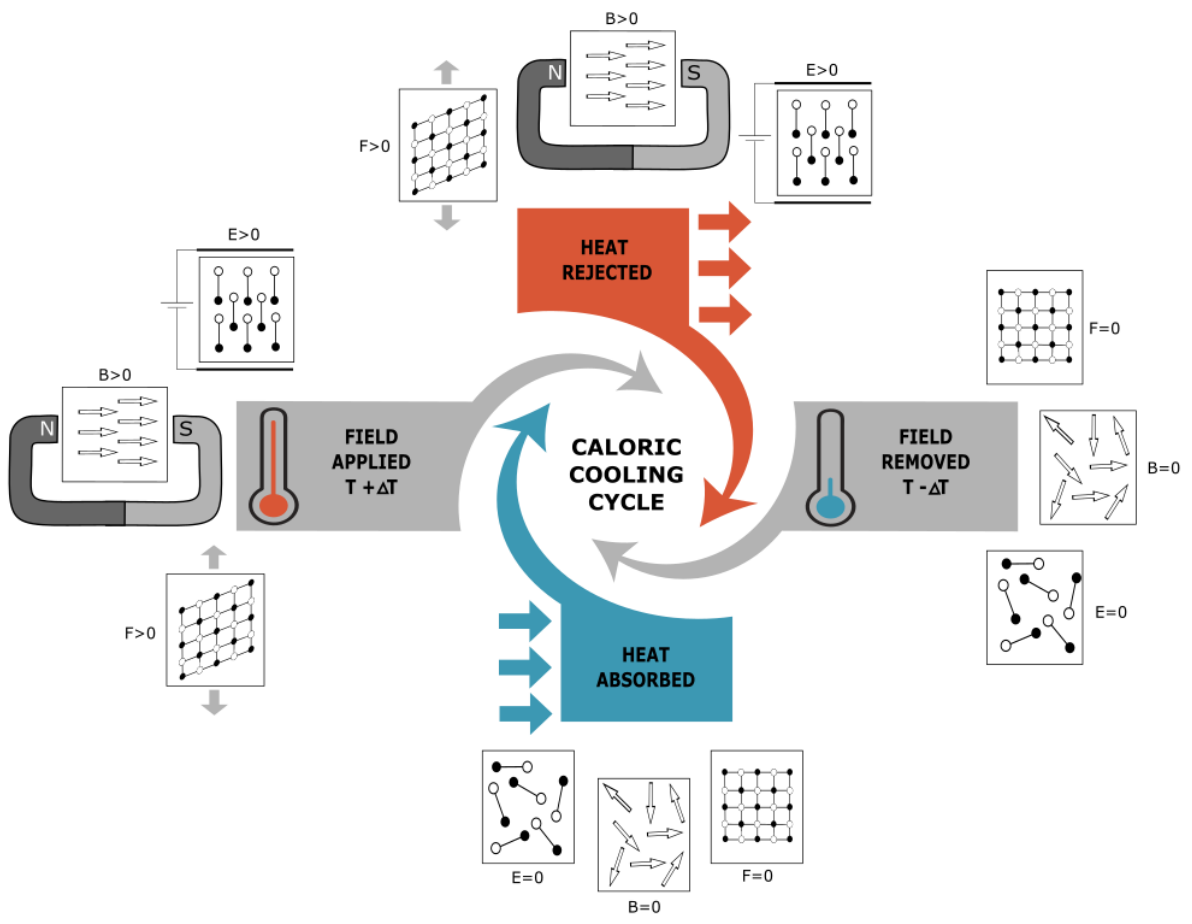

Fig. 1. Thermodynamic caloric cooling cycle.

In quasi-steady-state operation, a temperature span is established over the active caloric regenerator that substantially overcomes the adiabatic field change. The hot side of the active caloric regenerator is connected to the heat sink, and the cold side, to the heat source. The frequency of the operation of the active caloric regenerator is limited to a few $\mathrm{Hz}$, because of the high pumping-work input, which is a consequence of the high velocity of the oscillation and the viscous fluid (usually liquid water with a freezing depressant and corrosion inhibitors). Another limitation of the frequency comes from the need for convective heat transfer between the heat-transfer fluid and the caloric material. Devices with an active caloric regenerator can, therefore, only operate with a high energy efficiency over a limited range of low powers and small temperature spans between the heat source and the heat sink. Under such conditions, caloric devices exceed the mass (and cost) per unit of power, and in some cases are more than an order higher than vapour-compression devices [16-18].

In order to make caloric technologies competitive, a substantial improvement in their operating frequency is required (i.e., $10 \mathrm{~Hz}$ or higher) [19]. Under such conditions, active caloric regeneration cannot be efficiently applied. Instead, a serious alternative to active caloric regeneration is the use of special thermal control elements: thermal switches, thermal diodes and thermal regulators, which allow time- and location-dependent heat-flux control [19,30-32]. These elements have the potential to improve the energy efficiency, moreover, they enable a high power density (because of the high frequencies). 
The idea of controlling heat transfer using thermal control elements in caloric technologies was first proposed for electrocalorics by Basiulis et al. in 1988 [33]. However, such thermal control elements only became the subject of research in calorics much later (starting with Mathur and Mishchenko (2006) [34] and Epstein and Malloy (2009) [35] in electrocalorics and Kitanovski and Egolf (2010) [36] in magnetocalorics). Fig. 2 shows number of publications in the field of thermal control elements in calorics. The increased intensity of the research activities can be observed especially in the last decade.

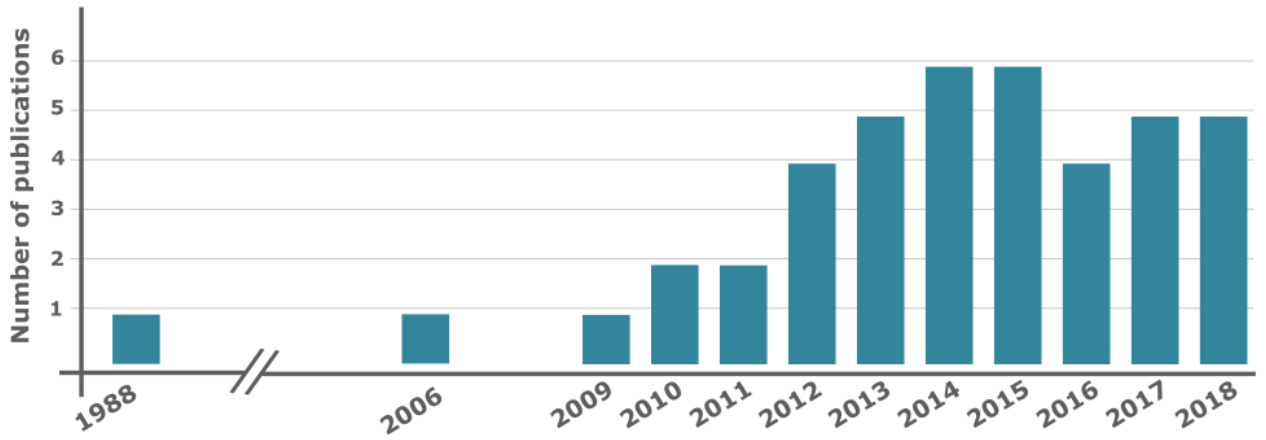

Fig. 2. Number of publications relating to thermal control elements in caloric technologies.

The objective of this paper is to provide information about the thermal control elements and their figures of merit. Furthermore, an up-to-date review of the existing research activities on the applications of thermal control elements in caloric technologies is presented, followed by a comparison with regards to their performance. Finally, guidelines for future research activities together with the targeted features and domains for thermal control elements that are most suitable for implementation in caloric energy conversion are defined.

\section{Thermal control elements}

Thermal control elements are used to limit the local and transient heat flux by varying the thermal resistance between the caloric materials and the heat source/sink. The thermal resistance $R$ (Eq. (1)) is the material's ability to resist the heat flux, analogous to electrical resistance. It is defined as the ratio of the temperature difference $\Delta T$ between the two sides of the body and the net heat flux $\dot{q}$ between them

$R=\Delta T / \dot{q}$

The thermal control element in calorics operates in the following manner. When the caloric material cools due to the caloric effect, the maximum heat flux has to flow from the heat source to the caloric material and no (or a minimal) heat has to flow from the heat sink to the caloric material (Fig. 3a). When the caloric material heats due to the caloric effect, the maximum heat flux has to flow from the caloric material to the heat sink, and no (or a minimal) heat has to flow from the caloric material to the heat source (Fig. 3b).

The single-stage application of thermal control elements in a caloric device is schematically presented in Fig. 3. However, there is also the option of a multi-stage application, such as a cascade arrangement of thermal control elements. The principle behind a cascaded thermal switch's implementation in a magnetocaloric device is described in $[19,37,38]$.

In order to achieve anisotropy in the heat fluxes between the heat sink and the heat source, depending on the temperature of the caloric material, the implemented thermal control elements require contrasting trends in terms of temperature- or time-dependent thermal resistance. Another important property of thermal control elements in calorics is the time response. In order to achieve high operating frequencies in caloric devices, the thermal control 
elements must have a rapid response time. Therefore, the switching time, which is needed for the switch/regulator to change between the "on" and "off" state, and the time response of the thermal diode, must be of the order $\tau \sim$ ms.

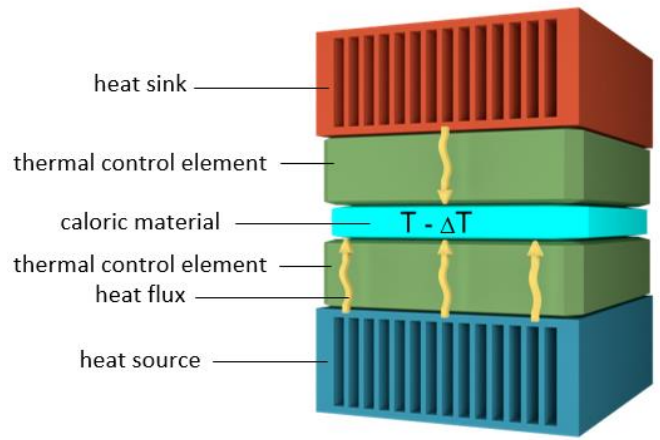

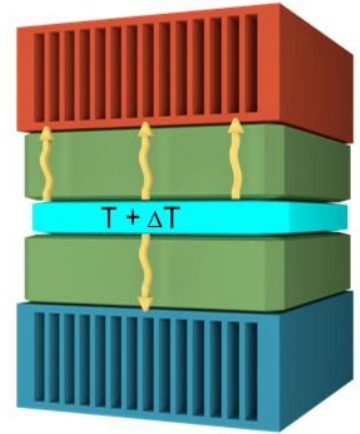

$\mathrm{b}$

Fig. 3. Example of the heat-flux direction during the operation of two thermal control elements, embedded with the caloric material and the heat sink/source, for a) a cooled and b) a heated caloric material due to the caloric effect.

For a clearer presentation, the different thermal control elements are presented in Fig. 4. The properties of these elements can be considered as being analogous with electrical elements. Namely, each of the thermal control elements is defined by its transfer function, related to the heat flux, which is analogous to the electrical current in electronics. The schematics show the dependency of the thermal resistance on external actuation in the case of a thermal switch and the temperature-dependent thermal resistance in the case of thermal diodes and regulators. Each thermal control element has two terminals, 1 and 2, at different temperatures, $T_{1}$ and $T_{2}$.

\section{Thermal switch \\ (electrical switch)}

The thermal resistance is time dependent - triggered actively by an external magnetic, electric, force or pressure field - which makes (the "on" state) or breaks (the "off" state) the thermal contact between the terminals 1 and 2. When the switch is "on", the thermal resistance is low and when the switch is "off", the thermal resistance is high. The thermal switch could be "on" when the external field is low (dashed line) or high (full line).
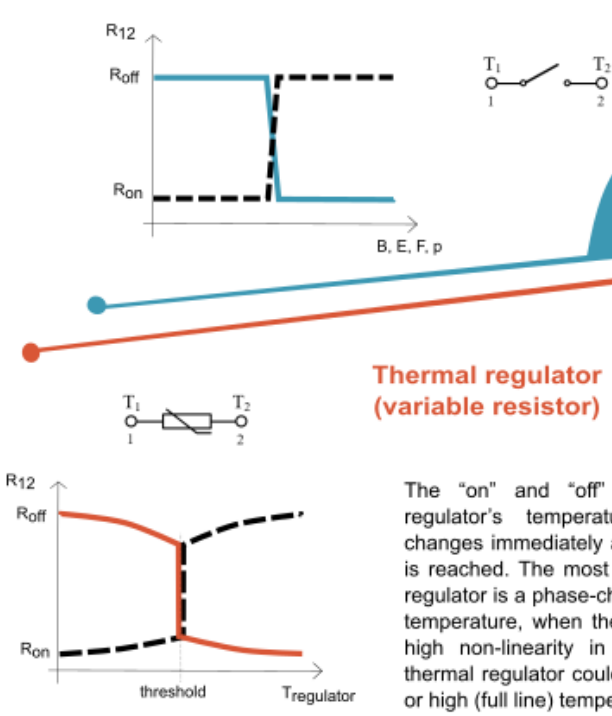

B, E, F, p
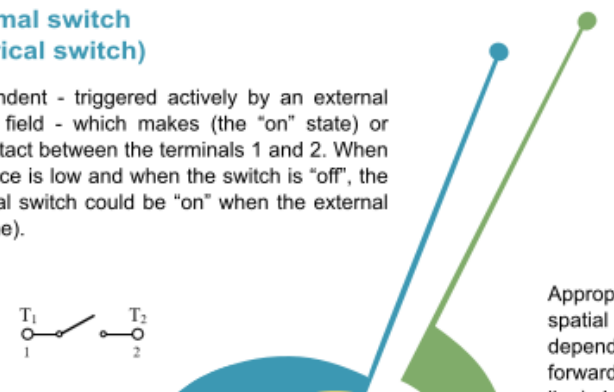

Thermal diode (electrical diode)

Appropriate materials for thermal diodes exhibit spatial anisotropy and non-linearity in temperature dependence. The thermal resistance is different for forward (full line) and reverse heat fluxes (dashed line). In analogy with electrical diodes, the therma diode has to operate at temperature differences above the threshold value in the forward direction and between zero and the breakdown temperature

difference in the reverse direction.

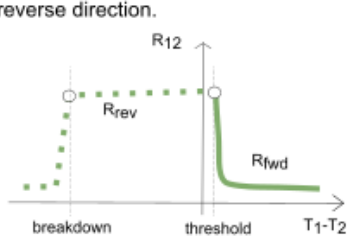

The "on" and "off" states are defined by the regulator's temperature. Its thermal resistance changes immediately after the threshold temperature is reached. The most obvious example of a thermal regulator is a phase-change material. At the threshold temperature, when the phase changes, we notice a high non-linearity in the thermal resistance. The thermal regulator could be "on" at low (dashed lined) or high (full line) temperatures.

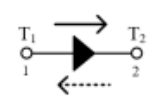
Thermal regulator
(variable resistor) 
Fig. 4. Definition of thermal control elements.

\section{Figure of merit for the thermal control elements}

Since the operation of a device strongly depends on the effectiveness of the thermal control element, it is important to define the figure of merit that corresponds to a particular type of element, i.e., thermal switch, thermal regulator or thermal diode. Because the presented thermal control elements operate in different ways, each has its own definition for the figure of merit. In general, the figure of merit for thermal control elements is defined at the same temperature difference between the "on" and "off" states or the "forward" and "reverse" heat-flux directions and for the net heat flux.

\subsection{Thermal switch}

In analogy with the electrical switch, the thermal switch can provide or block the thermal contact and the heat flux between two terminals that are at different temperatures. Ideally, when the switch is turned "on", the thermal resistance is zero and, vice-versa, the thermal resistance is infinite when the switch is turned "off". The figure of merit for thermal switches is therefore defined by the switching ratio, $r_{s w i t c h}$, (Eq. (2)) between the minimum and the maximum thermal resistance for the switch during the "on" and "off" states, where $R_{\text {off }}$ and $R_{\text {on }}$ represent the thermal resistance between the terminals during the "off" and "on" states, respectively.

$r_{\text {switch }}=R_{\text {off }} / R_{\text {on }}$

\subsection{Thermal regulator}

The figure of merit for thermal regulators is the switching ratio $r_{\text {regulator, }}$ which is defined as the ratio of the differential thermal resistance between the "off" and "on" states, respectively (Eq. (3)). The reason for this is that the temperature dependence of the thermal resistance is non-linear.

$$
r_{\text {regulator }}=R_{\text {off }} / R_{\text {on }}=\left(\frac{d T}{d \dot{q}}\right)_{\text {off }} /\left(\frac{d T}{d \dot{q}}\right)_{\text {on }}
$$

The thermal resistances $R_{\text {off }}$ and $R_{o n}$ represent the thermal resistance between the terminals during the "off" state and "on" states, respectively.

\subsection{Thermal diode}

The figure of merit for a thermal diode is related to the rectification ratio $r_{\text {diode }}$, as defined in Eq. (4). This ratio considers the asymmetry of the net heat flux in the forward $\dot{q}_{f w d}$ and reverse $\dot{q}_{r e v}$ directions at the same temperature difference and at a fixed average temperature between the terminals. If the heat flux in the forward direction is higher, the rectification ratio is calculated as

$r_{\text {diode }}=\frac{\left|\dot{q}_{f w d}\right|-\left|\dot{q}_{r e v}\right|}{\left|\dot{q}_{r e v}\right|}=\frac{\left|\left(\frac{d(\Delta T)}{d R}\right)_{f w d}\right|-\left|\left(\frac{d(\Delta T)}{d R}\right)_{r e v}\right|}{\left|\left(\frac{d(\Delta T)}{d R}\right)_{r e v}\right|}$

where $\dot{q}_{f w d}$ is the net heat flux in the forward direction and $\dot{q}_{r e v}$ is the net heat flux in the reverse direction.

\subsection{Combined figure of merit for thermal control elements in caloric technologies}


From the application point of view, we have to know which thermal control element provides the higher anisotropy in heat fluxes under the prescribed conditions in the caloric device. Therefore, we suggest a figure of merit that enables a direct comparison of the performance of the thermal switch, the thermal diode and the thermal regulator in a caloric device. The feature of caloric devices is that the temperature at the terminals of the thermal control elements changes periodically. And since the thermal switches and regulators are not ideal, they also allow heat transfer during the "off" state. Such an operation is similar to an undesired heat flux in the reverse direction at the thermal diode. Therefore, we define the caloric thermal rectification ratio as presented in Eq. (5).

$\varkappa=\left(\frac{\left|\dot{q}_{f w d}\right|-\left|\dot{q}_{r e v}\right|}{\left|\dot{q}_{\text {rev }}\right|}\right)_{\text {diode }}=\left(\frac{\left|\dot{q}_{o n}\right|-\left|\dot{q}_{o f f}\right|}{\left|\dot{q}_{o f f}\right|}\right)_{\text {switch/regulator }}$

\section{Review of past and present applications of caloric technologies}

The majority of research work on thermal control elements in caloric technologies relates to thermal switches. A few investigations have been made on thermal diodes, but no research activity on thermal regulators is evident so far. The classification of thermal elements into groups is based on the definition in Section 3 and might differ from the authors' classification. The most confusing definition relates to the Peltier element, a heat pump that can act as a thermal switch or a thermal diode. If the voltage to the Peltier element is switched on and off, the element will act as a thermal switch. This can be seen in Fig. 4, where the thermal resistance changes because of the applied voltage. However, Peltier elements exhibit nonlinearity in their temperature dependency as well as asymmetry in the heat flux's reverse and forward directions when turned on and experiencing a temperature difference on both sides. Therefore, the Peltier element acts as thermal diode if the voltage is applied constantly (Fig. 4).

In the next sub-sections, the operation of thermal switches and thermal diodes is presented as a review of the existing applications in caloric devices. To the best of our knowledge, no thermal regulators were implemented in caloric devices so far. The figures are generalized, each having two microchannel heat exchangers representing the heat source and the heat sink. The caloric material is coloured arctic blue, its temperature is denoted as $\mathrm{T} \pm \Delta \mathrm{T}$, depending on cooling (Figure $a$ ) or the heating (Figure $b$ ) of the caloric material due to the caloric effect. The thermal control elements are marked in green in every case. The thermal switches in need of an external voltage supply are connected to the electrodes and a voltage source (shown as a battery). The active electrodes are marked purple, while the inactive are coloured light blue. The heat flux is represented by yellow arrows. The figures are not to scale.

\subsection{Thermal switches in caloric technologies}

Hess et al. [39] presented a universal analytical model to describe cascading caloric cooling devices that use thermal switches or thermal diodes. The model, which is analogous to an electrical low-pass filter, enables the implementation of different caloric effects and the principles of a thermal switch or a thermal diode. It has been validated by comparing the results based on other numerical models or experiments.

\subsubsection{Magnetocalorics}

Tsukamoto et al. [40,41] designed and tested the idea of a solid-state refrigerator with the application of mechanically actuated thermal switches. An external actuator was used to bend the cantilever to make or break the physical contact with the caloric material and the heat source/sink, as presented in Fig. 5. The switch is "on" when the switch is in physical contact with the caloric material and "off" when there is no physical contact. The device was experimentally tested using a lanthanum-based magnetocaloric alloy. The performed switching ratio was $r_{\text {switch }}=22.5$ for a $5.5 \mathrm{~s}$ switching time. 

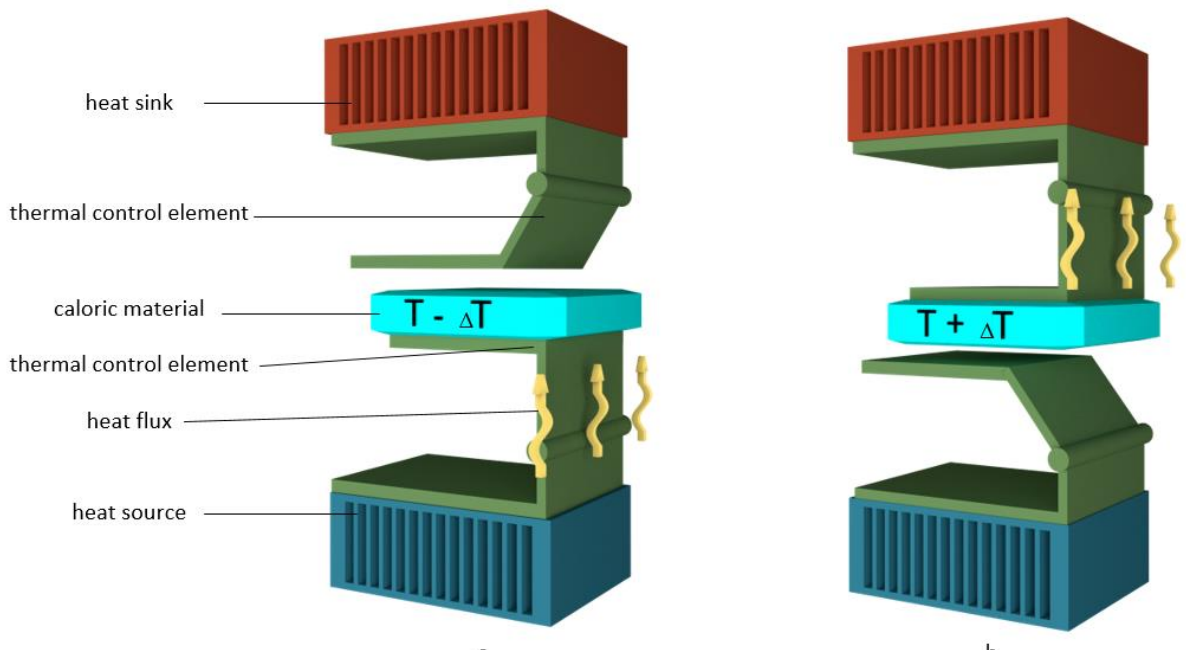

Fig. 5. Mechanically actuated cantilever thermal switch. The cantilever is pressed down by the external force, thus making a mechanical contact with the caloric material. Depending on the temperature of the caloric material, an appropriate heat-transfer connection is established. The figure has been re-drawn from [40,41].

Tasaki et al. [37] developed an idealised numerical model that enabled a comparison between an in-vehicle magnetic refrigeration system with an active magnetocaloric regenerator (AMR) and a magnetic refrigerator that uses thermal switches. Both the considered theoretical systems consisted of heat baths for the heat sink and the heat source, permanent magnets and magnetocaloric slabs. The odd and even magnetocaloric slabs were considered to be magnetized (heated up) and demagnetized (cooled down) at the same time. Fig. 6 presents the concept of a device with thermal switches.

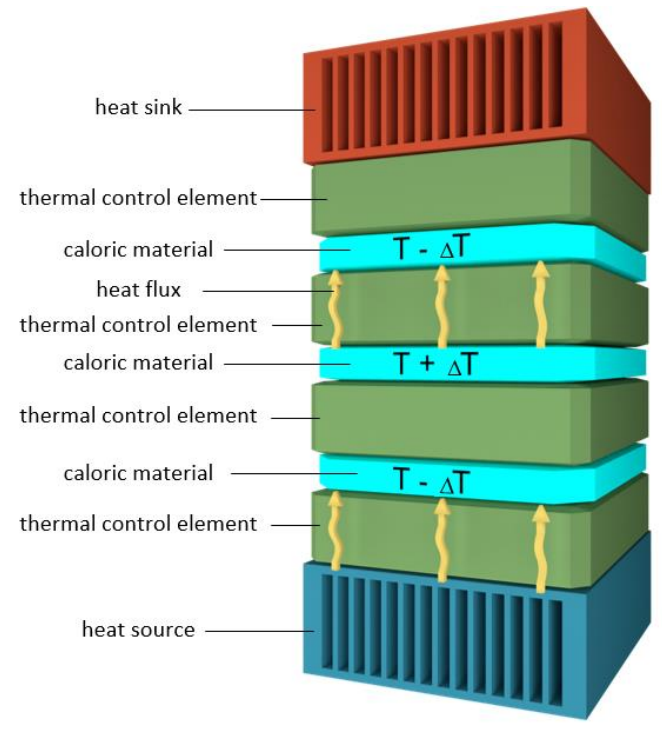

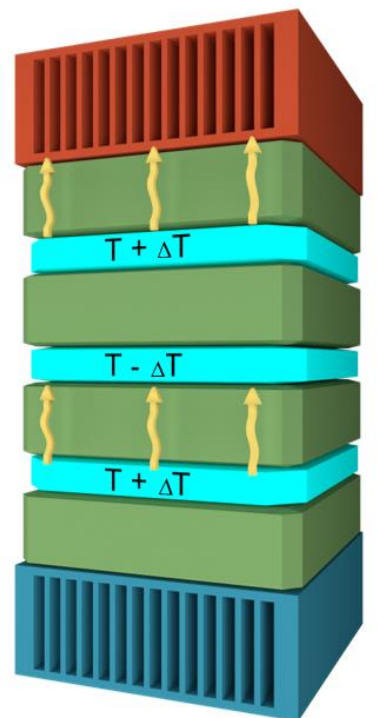

b

Fig. 6. Operation of a thermal switch and the magnetocaloric material assembly for two different operating phases a) and b): the odd and even magnetocaloric material slabs are heated up or cooled down by the magnetocaloric effect at the same time. This kind of operation enables heat transport from the heat source to the heat sink. The figure has been re-drawn from [37]. 
Each magnetocaloric slab was considered to be sandwiched between two thermal switches, which alternately turned "on" and "off". The heat transfer in this model was based on an ideal heat transfer between the magnetocaloric slabs: infinite thermal resistance during the "off" state and zero thermal resistance during the "on" state. The results of the study revealed that the application of the thermal switch leads to a higher cooling-power density when compared to the AMR concept.

Additional numerical simulations were performed by Olsen et al. [42] in order to improve the theoretical investigation of [37]. The comprehensive parametric analysis with different ideal properties of the magnetocaloric materials and the thermal switches led to results that demonstrated the limits of the considered system with regards to the maximum temperature span. The results again confirmed the advantage of thermal switches over an AMR, with the former having a cooling-power density that is 3.5-times higher.

Silva et al. [43], in their theoretical study, considered thermal switches made from an artificial material, the thermal resistance of which is manipulated by an external magnetic field. For the purposes of the numerical study, gadolinium was considered to be sandwiched between two thermal switches. The concept is schematically presented in Fig. 7. In order to achieve an efficient heat transfer between the heat source and the heat sink, the thermal switches have to exhibit contrasting trends in thermal resistance. The switch next to the heat source was considered to have a low thermal resistance in the absence of a magnetic field (Fig. 7a), and an idealized, zero thermal resistance at an applied external magnetic field (Fig. 7b). A similar, but inverse, situation was considered for the thermal switch that was attached to the heat sink. The results of the simulation showed a maximum specific cooling power of 2.75 $\mathrm{W} / \mathrm{cm}^{2}$ for an operating temperature heat sink of $296 \mathrm{~K}$ under a magnetic field change of $1 \mathrm{~T}$. The achieved temperature span for a COP of 1.5 was $2.5 \mathrm{~K}$. Later on, Silva et al. [44] upgraded the numerical model to a cascade system. This led to an increase in the temperature span from $2.5 \mathrm{~K}$ to11.5 K.

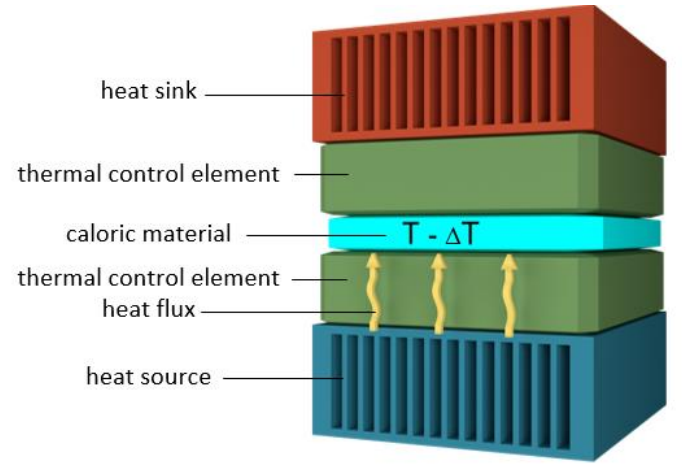

a

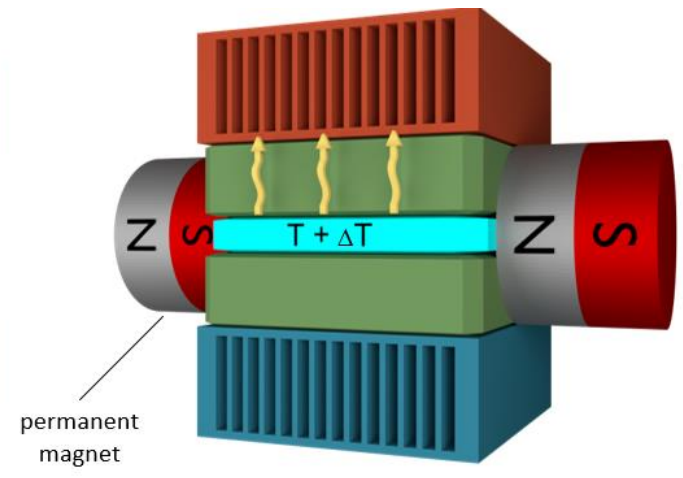

b

Fig. 7. Operation of a virtual thermal switch exhibiting a magnetic field dependence on the thermal resistance. The figure is re-drawn from [43].

Tomc et al. [45] numerically evaluated the idea of implementing micro-Peltier modules as thermal switches for magnetocaloric devices. Fig. 8 presents only one part of the whole device; the actual device was considered to consist of a row of micro-Peltier modules and magnetocaloric slabs: magnetocaloric material was sandwiched between two rows of the micro-Peltier modules, the heat sink and the heat source were added to the outer sides of the micro-Peltier modules. For the heat sink and the heat source, microchannel heat exchangers were considered with a water flow that was thermally controlled by heat baths. During the numerical simulation, the Peltier modules were alternatively turned "on" and "off", thus transferring heat from the heat source to the heat sink. The simulations showed that the Peltier modules could theoretically reach operating frequencies above $200 \mathrm{~Hz}$, where the coolingpower densities were between 2 and $10 \mathrm{~kW} / \mathrm{kg}_{\mathrm{mcm}}$. 


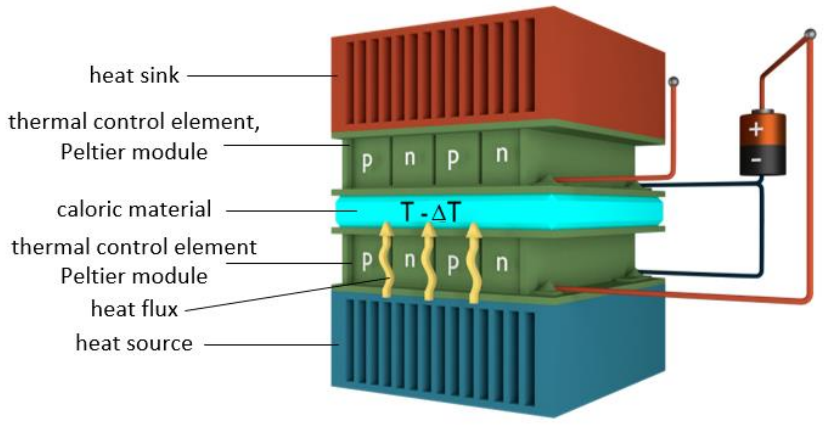

a

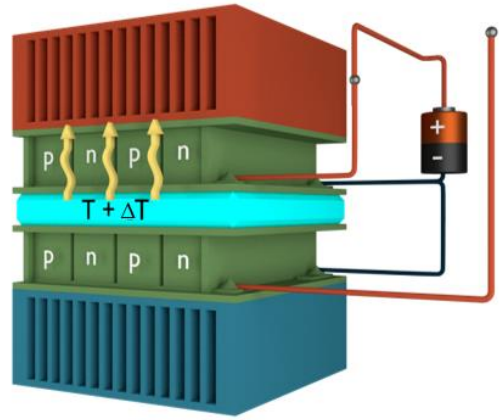

b

Fig. 8. Application of Peltier modules as thermal switches in a magnetocaloric refrigerator. The figure has been re-drawn from [45].

Tomc et al. [46] further theoretically compared the operation of two different magnetic refrigerators: one with a parallel-plate AMR and the second with micro-Peltier thermal switches. The comparison showed that at operating frequencies above $20 \mathrm{~Hz}$ the energy efficiency of the magnetocaloric device with micro-Peltier thermal switches drastically increased.

Egolf et al. [47], similar to Tomc et al. [46], theoretically evaluated the performance of Ni-nanowire-based Peltier modules used as thermal switches in a magnetocaloric refrigerator. The comparison was made between the usual magnetic refrigerator with an AMR and the Peltier-thermal-switch-based magnetic refrigerator. The results revealed that the device with thermal switches can operate with a 5-times higher operating frequency and power density than the comparable AMR-based device. Consequently, the mass of magnets was three times smaller in the case of the thermal switches. The author's main idea behind implementing the Peltier modules was to drive them with the currents induced by the varying magnetic field, which is required in magnetocalorics. However, the concept was not experimentally tested.

Monfared [38] suggested applying a sequence of Peltier modules and magnetocaloric slabs, as presented in Fig. 9. In order to guide the heat from the heat source to the heat sink, the Peltier modules had to be switched "on" and "off" alternately, depending on the temperature of the surrounding magnetocaloric slab. This study showed that the application of a Peltier module can only enhance the heat transfer if the Peltier modules operate under optimized conditions. The results of a simulation for five layers of magnetocaloric material showed a specific cooling power of $156 \mathrm{~W} / \mathrm{kg}_{\mathrm{mcm}}$ at an operating frequency of $10 \mathrm{~Hz}$, with a corresponding COP of 0.96, with the temperatures of the heat sink and the heat source being $295.15 \mathrm{~K}$ and $290.15 \mathrm{~K}$, respectively.

Micro-Peltier modules were also considered as thermal switches in a numerical study of de Vries and van der Meer [48]. The concept of the device had a similar structure to the one in Tomc et al. [45]. In contrast to other authors, they more accurately modelled the thermoelectric effect, but did not take into account the mean field theory for the magnetocaloric effect. The results of the parametric analysis provided a less optimistic outlook for the application of micro-Peltier modules as thermal switches. The authors argued that a heat pump based only on Peltier modules performed better than a combination of a micro-Peltier module with a magnetocaloric material. The comparison was made at an operating frequency of $20 \mathrm{~Hz}$ and a magnetic field of $1 \mathrm{~T}$. 


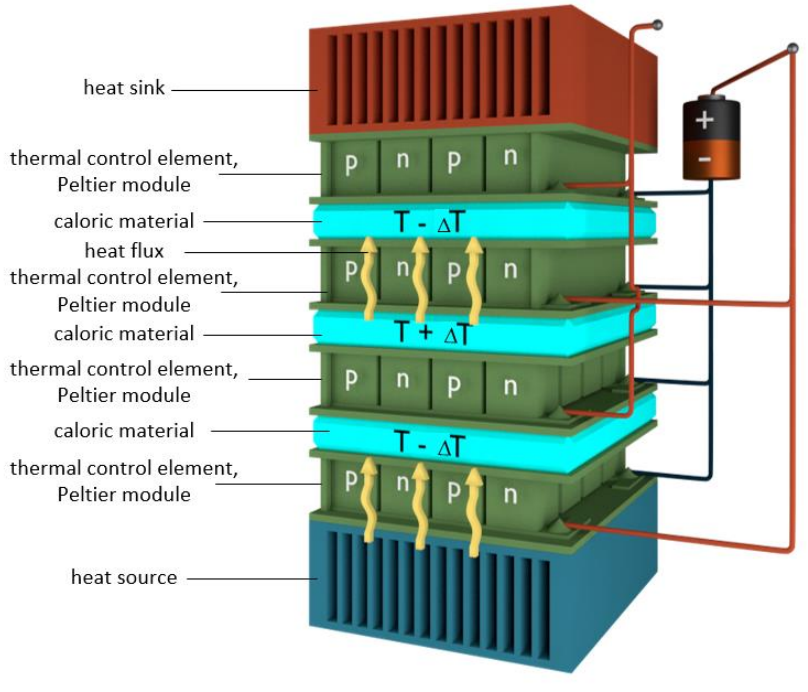

a

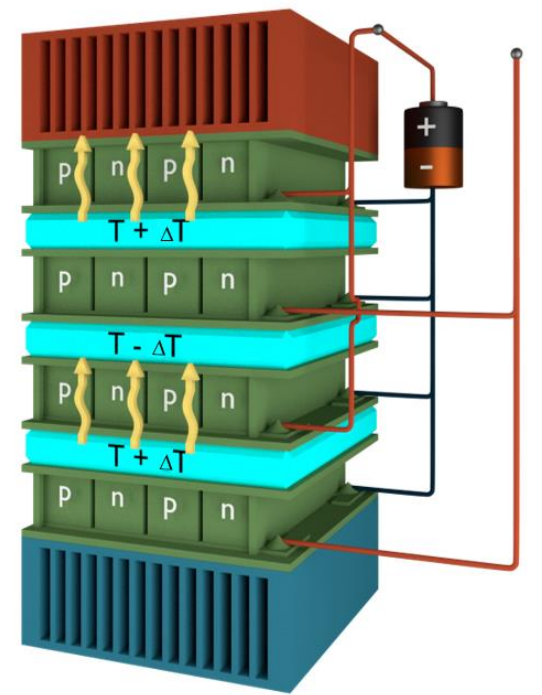

b

Fig. 9. Operation of Peltier modules as thermal switches within the magnetocaloric material assembly for two different operating phases. The figure has been re-drawn from [38].

Puga et al. [49] experimentally analysed the idea of a thermal switch based on a ferrofluid that could be implemented in magnetocalorics. The ferrofluid was placed inside a closed container, with the heat source at the bottom and the heat sink at the top, as depicted in Fig. 10. When no external magnetic field was applied, the ferrofluid was in contact with the heat source, as gravity was the only force present. When the magnetic field was applied, the ferrofluid moved towards the heat sink, rejecting the heat. The authors proved the concept at frequencies up to 30 $\mathrm{Hz}$ with optimistic results, but did not implement the switch in a magnetocaloric device.

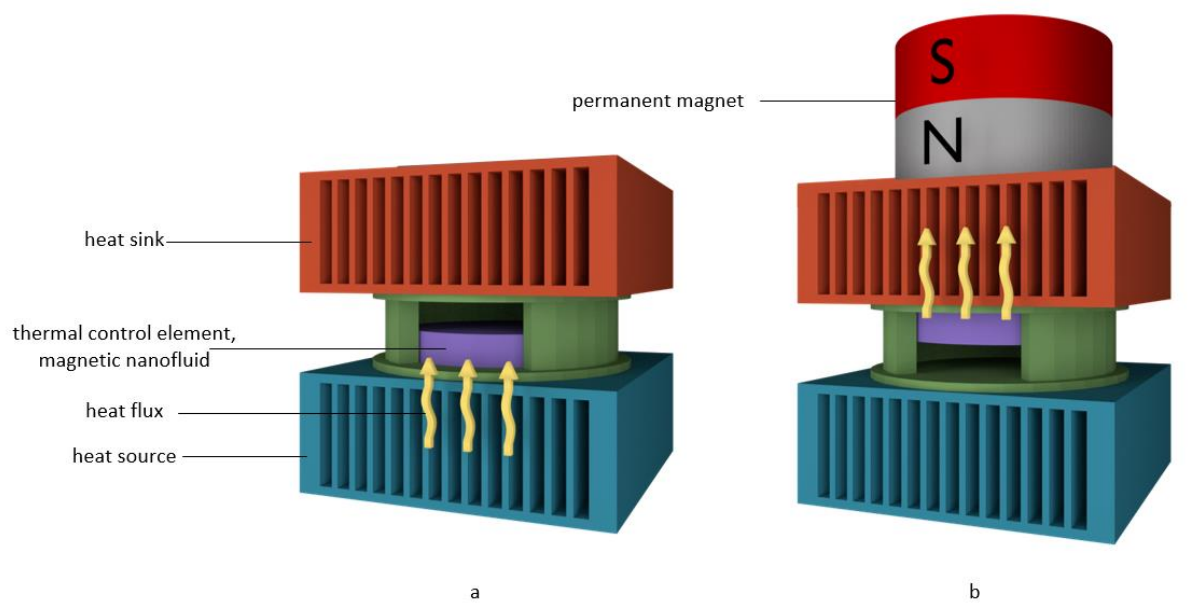

Fig. 10. Thermal switch based on ferrofluid. The figure has been re-drawn from [49].

Wu et al. [50] proposed a numerical simulation of a magnetocaloric refrigeration system, considered to consist of two rotating discs carrying magnetocaloric material slabs, as presented in Fig. 11. One semi-annular permanent magnet was placed around each rotating disc, providing a magnetic field over the opposite halves of each disc area. Between the two discs, a fixed heat-transfer disc was sandwiched. The heat-transfer disc was made of copper, which enhanced the heat transfer between the upper and lower magnetocaloric discs. The upper and lower disks rotated in opposite directions, providing heat regeneration with the help of the middle plate, similar to an active caloric 
regenerator. The heat was transferred to the heat source/heat sink, which were located at the hottest and the coldest parts of the system. The results of the simulations demonstrated the $50.9 \mathrm{~K}$ maximum temperature span between the hot and cold ends for a magnetic field change of $1.5 \mathrm{~T}$. The maximum specific cooling power was $105.8 \mathrm{~W} / \mathrm{kg} \mathrm{mcm}$. The numerical model was validated with experiments.

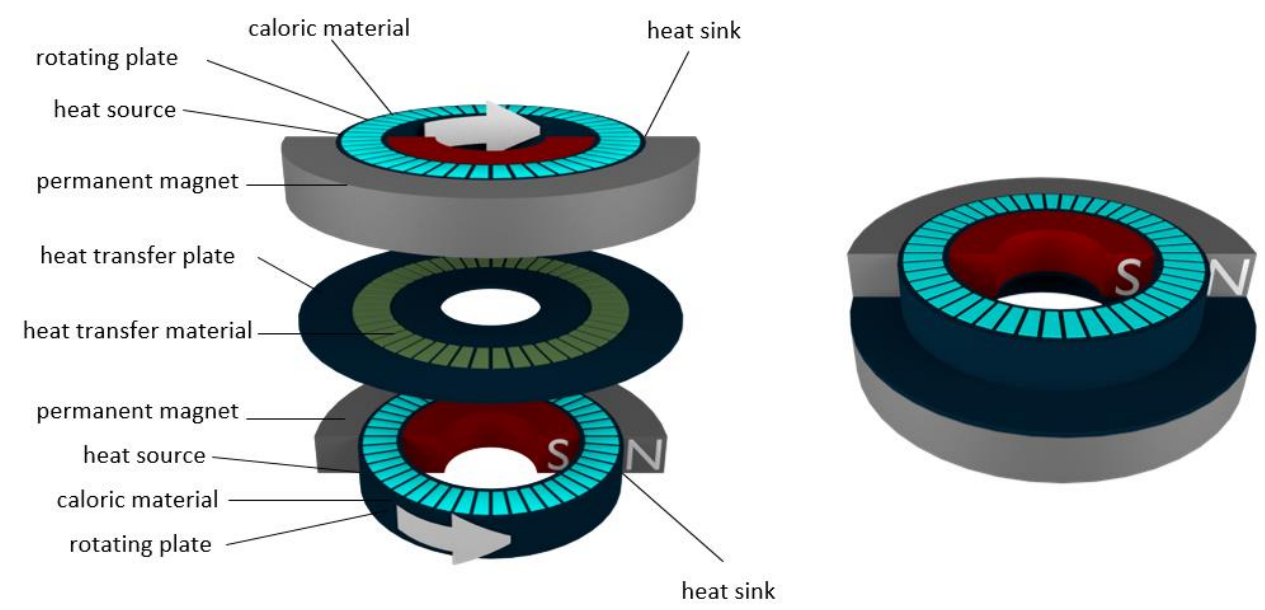

Fig. 11. Rotating magnetocaloric refrigerator with thermal switches. The figure has been re-drawn from [50].

Lu et al. [51] further improved the numerical system presented by Wu et al. [50]. The authors proposed modifying the middle, fixed heat-transfer disc, which would improve the heat transfer. The author suggested the addition of Peltier elements and topology-optimized, high-thermal-conductivity slabs made of copper. The simulated operation of the device showed improved performance: the copper slabs improved the specific cooling power by a minimum of $32 \%$. The model was experimentally validated by a heat-transfer analysis between the elements.

Kitanovski et al., in their book [19], presented the concept of different thermal switches for magnetocaloric devices. Among others, the most detailed explanation is for microfluidic switches, based on electrowetting principles. Other principles cover Peltier thermal switches, electrocapillary flow, electrophoresis, electrosmosis, electrorheology, magnetohydrodynamics, ferrohydrodynamics and magnetorheology.

\subsubsection{Electrocaloric}

Epstein and Malloy [35] numerically evaluated the application of thermal switches made of liquid crystals. The liquid crystals exhibited a switching ratio of the order $r_{\text {switch }} \sim 3$ [52] in thermal resistance between the parallel and perpendicular directions of the molecular director. By applying a voltage across the electrodes on both sides, the thermal resistance changes in a time period of ms. Fig. 12 presents the proposed implementation of liquid crystals in a caloric device.

Khodayari and Mohammadi [53] performed numerical simulations of a solid-state refrigerator based on the heat conduction between electrocaloric elements and heat-conducting elements. They showed that alternate switching of the electrocaloric effect enabled the heat transfer from the heat source to the heat sink. The device was considered to consist of an electrocaloric element where one side is connected to an aluminium slab and the other to a copper slab. The simulation resulted in a $6 \mathrm{~K}$ temperature span between the heat sink and the heat source at a $1-\mathrm{kV} / \mathrm{mm}$ applied electric field change on a PMN-25PT electrocaloric material at an operating frequency of $1 \mathrm{~Hz}$. 


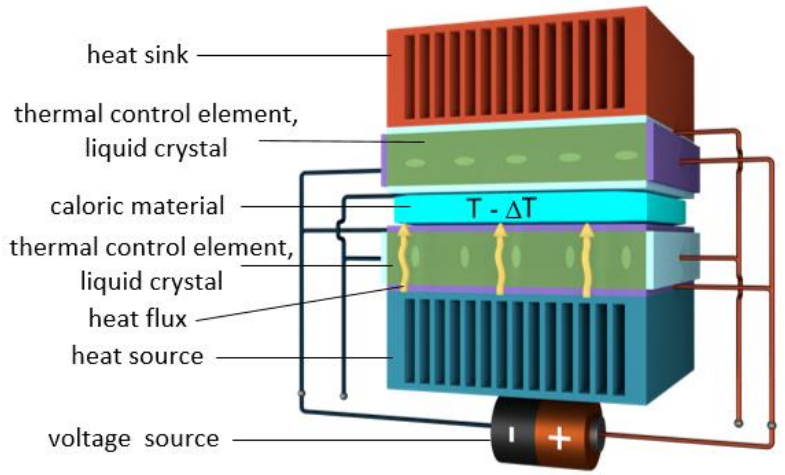

a

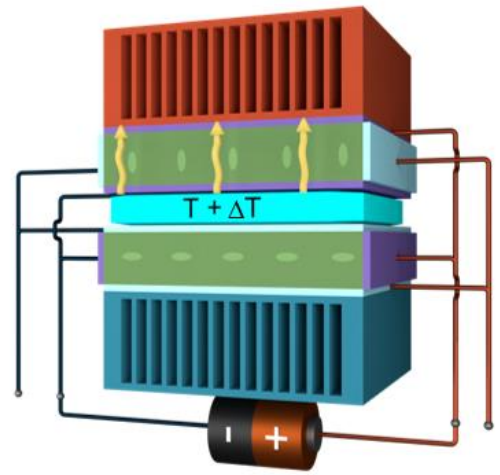

b

Fig. 12. Liquid-crystal thermal switch for electrocalorics. The figure has been re-drawn from [35].

Another coupled mechanical-fluidic thermal switch was studied by Jia and Ju [54], who also experimentally validated the numerical model. The electrocaloric material was fixed on an external actuator, which moved it between the heat source and the heat sink. The mechanical movement of the thermal capacitor was coupled with the electrocaloric effect. In order to decrease the contact resistance, discrete droplets were attached to the solid heat sink and the heat source. The lithographically patterned hydrophilic islands enabled reversible shape changes of droplets while moving the substrate towards and away from the heat source and the heat sink. The concept of the device is presented in Fig. 13. With a switching ratio of more than 100 and an operating frequency of $0.3 \mathrm{~Hz}$, the specific cooling power was $500 \mathrm{~W} / \mathrm{m}^{2}$.
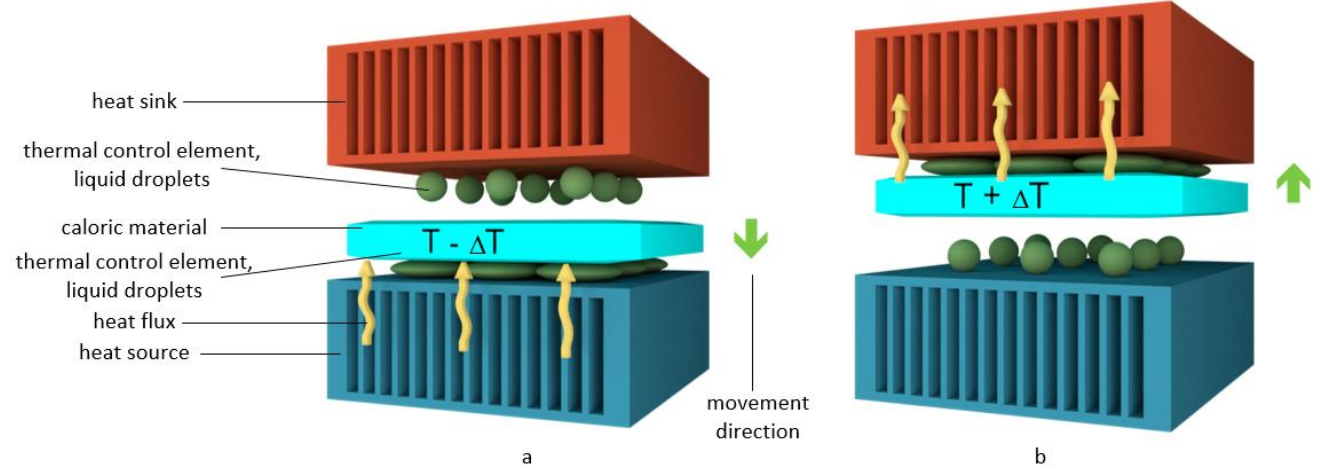

Fig. 13. Coupled mechanical-fluidic thermal switch. A motorized stage was used to move the caloric material. The figure has been re-drawn from [54].

Chukka et al. [55] experimentally tested an electrocaloric cooling device using PMN-PT as the electrocaloric material. The caloric material was sandwiched between two Peltier thermal switches and the heat source and the heat sink were placed on each outer side of the Peltier thermal switch. The device's concept is very similar Tomc et al. [45], presented in Fig. 8. The Peltier elements were considered to be alternately switched "on" and "off" in the opposite phase to ensure the right direction of the heat flux. The cooling device's performance was evaluated by cooling a $10-\mathrm{W}$ chip. The normal cooling rate of the chip was $2.3 \mathrm{~K} / \mathrm{min}$, but higher in the case of cooling using Peltier thermal switches and the electrocaloric refrigeration principle. The optimum cooling rate achieved was 5.4 $\mathrm{K} / \mathrm{min}$, at an applied electric field of $12 \mathrm{kV} / \mathrm{cm}$ and an operating frequency of $0.42 \mathrm{~Hz}$.

Hehlen et al. [56] proposed and experimentally tested a thermal switch based on electrohydrodynamic (EHD) propulsion, by causing an internal convection within the dielectric fluid. The commercially available ceramic, multilayer chip capacitors used as the electrocaloric material were inserted between the two thermal switches. Each 
thermal switch was made of a $1 \mathrm{~mm}$ gap filled with a dielectric fluid. The electrodes were patterned on each side of the gap, being in thermal contact with either the heat source or the heat sink. The operation of such a caloric device is presented in Fig. 14. The experiments using a dielectric fluid called hydrofluoroether showed a switching ratio of $r_{\text {switch }}=4.7$ at an applied voltage of $390 \mathrm{~V}$ and an operating frequency of $25 \mathrm{mHz}$. The established temperature span between the heat sink and heat source was $1.5 \mathrm{~K}$, which was three times the adiabatic temperature change of the electrocaloric material.

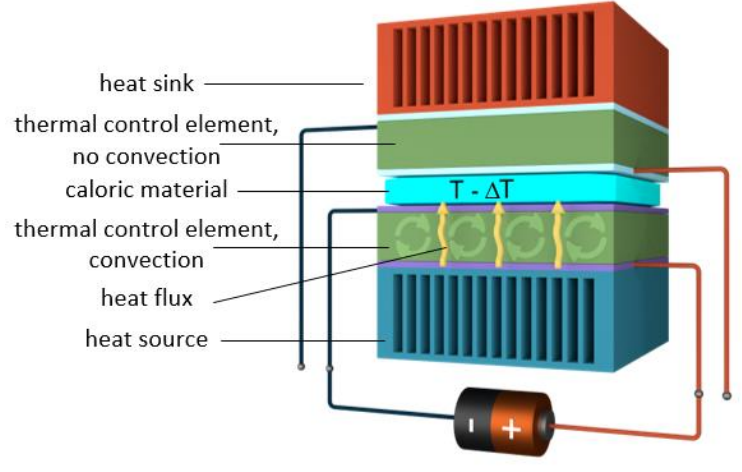

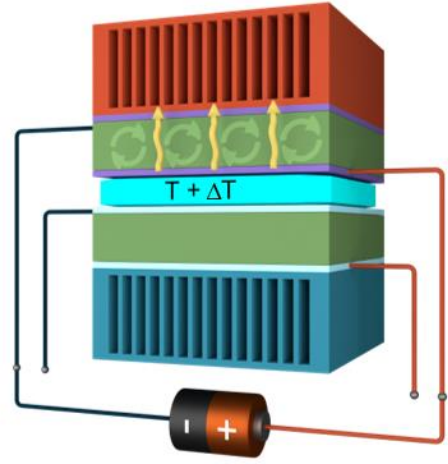

b

Fig. 14. Dielectric fluidic thermal switches exhibiting EHD convection. The figure has been re-drawn from [56].

Gu et al. [57,58] proposed two ideas for applying heat regeneration in electrocaloric devices: the rotary electrocaloric refrigerator [57] and electrocaloric oscillatory device ECOR [58]. The thermal regeneration in ECOR was obtained by reciprocating motion actuator, which moved stainless-steel regenerators in and out of the housing. The motion of the regenerator was synchronized with the electrocaloric effect of the EI-copolymer, which was fixed inside the housing. In order to reduce the friction and thus the heat generation, a low-viscosity lubricant was applied to the surface between the moving parts. The simulations were experimentally validated at low operating frequencies. During the experiment, the device achieved a $5 \mathrm{~K}$ temperature span between the hot and cold ends in steady-state operation at a frequency of $0.5 \mathrm{~Hz}$. The rotary electrocaloric refrigerator of $\mathrm{Gu}$ et al. [57] was only numerically evaluated. The main purpose of the device was to perform heat regeneration without a heat-transfer fluid, i.e., only by the conduction and movement of the electrocaloric elements. The operating principle of the idea is very similar to the work of Wu et al. [50] presented in Fig. 11 (see Section 4.1.1. for additional information). The main difference compared to the work of $\mathrm{Wu}$ et al. [50] was in the use of an electrocaloric material instead of a magnetocaloric one.

Some polymers and ceramics exhibit a simultaneous electrocaloric effect and a displacement or bending of the material. Several thermal switches coupling electrocaloric and electromechanical effects were numerically and experimentally evaluated by Ju [59], Bradeško et al. [60], Ma et al. [61] and Almanza et al. [62]. The generalized view of the concept is presented in Fig. 15. When the electrocaloric material was cooled, the stack was bent towards the heat source (a) and when heated up, the stack was bent towards the heat sink (b).

$\mathrm{Ju}$ [59] theoretically evaluated the design concept of a thermal switching mechanism in an electrocaloric device, where the micro-electrocaloric cooling module was fixed on both sides via silicon flexure. The electrocaloric capacitor was moved up and down in periods of the order of ms, making a thermal contact with either the heat sink or the heat source, like presented in Fig. 15. The results showed a switching ratio of $r_{\text {switch }}=1000$ and a cooling power of $10 \mathrm{~W} / \mathrm{cm}^{2}$. 

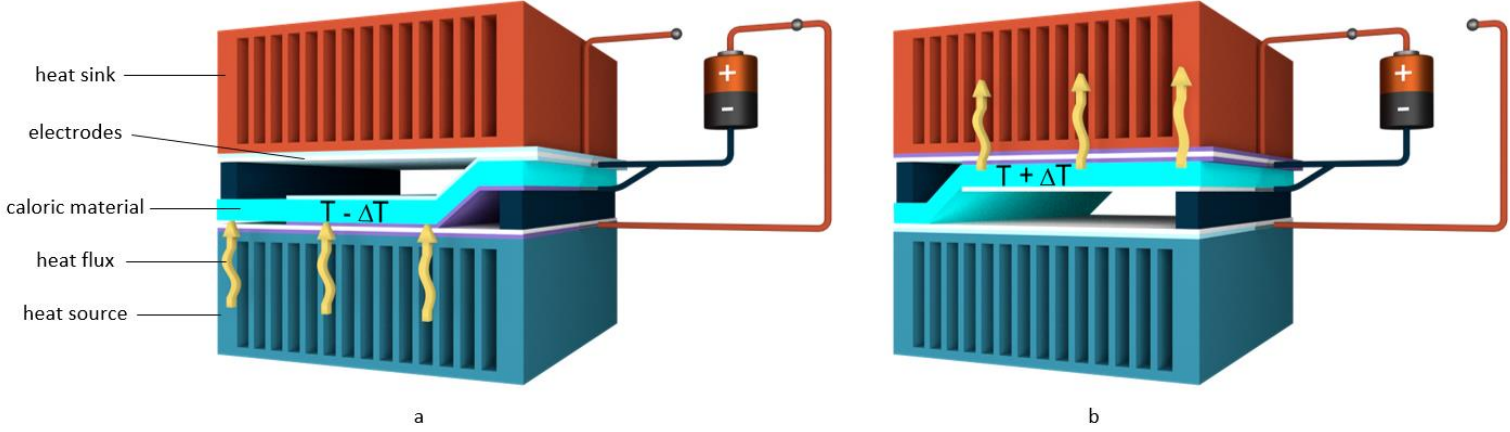

b

Fig. 15. Mechanically actuated thermal switch made of electrocaloric material that simultaneously exhibits the electrocaloric and electromechanical effects. The figure has been re-drawn from [61].

Bradeško et al. [60] implemented PMN-35PT elements that were attached on one side and free to bend on the other. The approach was numerically tested, where thermal resistance in the "off" state was considered to be infinitely high, so the switching ratio $r_{\text {switch }}=\infty$. The simulation was performed for a device with 15 stacked electrocaloric materials, with a $1.2 \mathrm{~K}$ adiabatic temperature change, which led to a $12.6 \mathrm{~K}$ difference between the first and the last element for a specific cooling power of $2340 \mathrm{~W} / \mathrm{kg}$.

Another switch was experimentally tested by Ma et al. [61]. The authors fixed the electrocaloric polymer stack on both sides and electrostatically actuated it with an "s" shape between the heat source and the heat sink, as presented in Fig. 15. They applied P(VDF-TrFE-CFE) as the active electrocaloric material and carbon nanotubes for the electrodes. Due to optimized size, the switching time was less than $30 \mathrm{~ms}$. They tested the device by cooling down a mobile-phone battery: the normal cooling rate of the battery in the air was $0.06 \mathrm{~K} / \mathrm{s}$, and $1.6 \mathrm{~K} / \mathrm{s}$ in the case of the electrocaloric cooling, when the applied electric field change was $66.7 \mathrm{MV} / \mathrm{m}$ and the operating frequency was $0.8 \mathrm{~Hz}$. This resulted in a specific cooling power of $2.8 \mathrm{~W} / \mathrm{g}$ for the electrocaloric material.

Another numerical model for characterization of thin film thermal switches was proposed by Almanza et al. [62]. The film deflected under applied voltage, making or breaking the contact with either heat sink or heat source. Their testing device contained only one switch as the proof of the concept and which served for the characterization of the thermal resistances. The results of the simulations revealed a switching ratio of $r_{\text {switch }}=1000$ and a switching time of several seconds.

Smullin et al. [63] developed a numerical model that made it possible to analyse the operation of an electrocaloric heat pump based on the thermal-switch principle. They showed the impact of the operating frequency and the thermal properties of thermal switches and electrocaloric capacitors on the cooling power and the efficiency of the electrocaloric device. The model was experimentally validated. They implemented electromechanically actuated thermal switches with a switching ratio of $r_{\text {switch }}=27$. The highest temperature difference between the heat source and the heat sink was $0.22 \mathrm{~K}$ at an operating frequency of $0.3 \mathrm{~Hz}$ with a maximum adiabatic temperature change of $0.5 \mathrm{~K}$.

Hirasawa et al. [64] proposed concepts for two different thermal-switch mechanisms, which were numerically evaluated: a mechanical contact thermal switch and a fluidic thermal switch. In the case of the mechanical contact thermal switch, the electrocaloric film was considered to be sandwiched between the heat source and the heat sink. A thermal switch, i.e., a thin aluminium foil, was considered to be placed on each side of the caloric material. During the operation of the electrocaloric device, the switch was considered to move between the caloric material and the heat source/sink, thus transferring the heat. The movement was synchronized with the electrocaloric effect. The switching ratio $r_{\text {switch }}=100$ was calculated on the basis of the thermal contact resistance, depending on the contact pressure. The concept was tested in a simulation with an operating frequency of $1000 \mathrm{~Hz}$ at a $10 \mathrm{~K}$ temperature span 
between the heat source and the heat sink, where the average cooling power was calculated to be $70 \mathrm{~kW} / \mathrm{m}^{2}$ of the switch area.

The theoretical concept of the fluidic thermal switch of Hirasawa et al. [64] was based on an air-water slug flow in the two channels located above and below the electrocaloric material. Each channel was attached to either the heat sink or the heat source (Fig. 16). Water served as the thermal conductor (lower thermal resistance) and air as the insulator (higher thermal resistance). The interaction between the slug flow and the electrocaloric effect was controlled in such a way that the water enabled the periodic switch of the heat flux from the hot caloric material to the heat sink and the heat flux from the heat source to the cold caloric material. During the heat transfer between the electrocaloric material and the heat sink/source by water, the switch was in the "on" state. During the "off" state, the air acted as the thermal insulator between the caloric material and the heat source/sink. The simulation was conducted with water in the upper channel at the inlet, being $5 \mathrm{~K}$ above the ambient temperature, and the temperature of water in the lower channel at the inlet, being $5 \mathrm{~K}$ below the ambient temperature. The thickness of the electrocaloric material was considered to be $200 \mu \mathrm{m}$ and the channel diameter $100 \mu \mathrm{m}$. The concept was tested in a simulation at an operating frequency of $10 \mathrm{~Hz}$, where the average cooling power was calculated to be $13 \mathrm{~kW} / \mathrm{m}^{2}$ of the switch area.

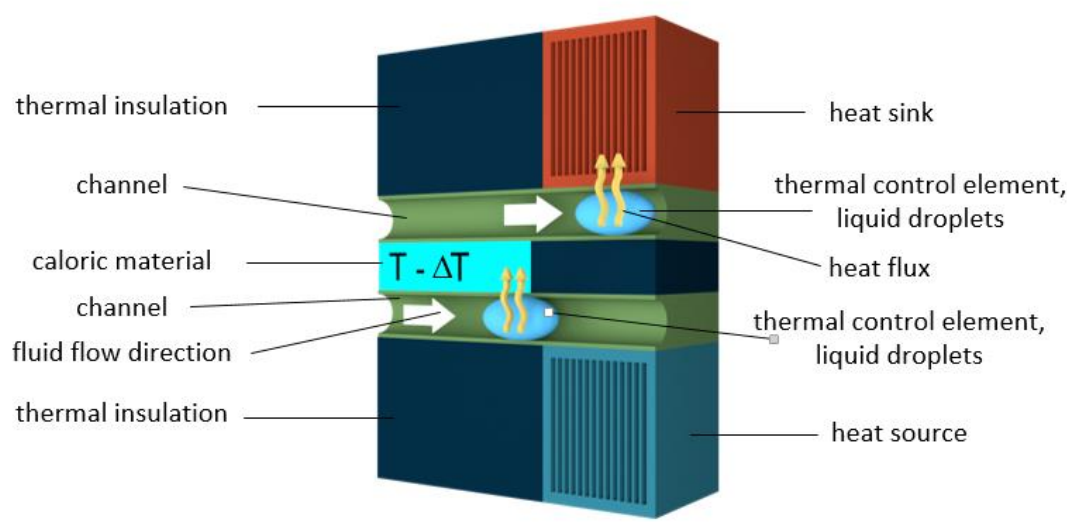

a

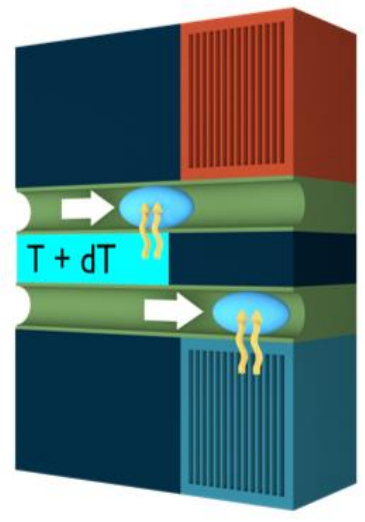

b

Fig. 16. Fluidic thermal switch applying air-water slug flow to alternately transfer the heat from/to the electrocaloric material. The figure has been re-drawn from [64].

Wang et al. [65,66] designed and tested different variations of mechanically actuated silicon thermal switches. The type that was the easiest to implement in the electrocaloric device was further tested. The electrocaloric device consisted of $\mathrm{B} \mathrm{BaTO}_{3}$ electrocaloric multilayer capacitor that was inserted between two thermal switches, as shown in Fig. 17. Each switch consisted of two parts with a complementary etched groove pattern, which made or broke the thermal contact with the electrocaloric material. The moving parts of each switch were fixed to the external actuator, where the movement of the actuator was synchronized with the electrocaloric effect. A thin layer of lubricant was applied to the interface to reduce the heat generation caused by the friction. The maximum achieved temperature span was $0.3 \mathrm{~K}$, which was $60 \%$ of the adiabatic temperature change of the electrocaloric material under the applied electric field. The switching ratio of the switch was $r_{\text {switch }}=27$, while the switching time was less than $13 \mathrm{~ms}$.

The authors further enhanced the heat transfer to and from the electrocaloric material by implementing anisotropic heat-conductive plates made of layers of electrocaloric material and FR-4 PCB, which served as an insulator [67]. They achieved a $2.5 \mathrm{~K}$ temperature span or five times the adiabatic temperature difference of the electrocaloric material. 

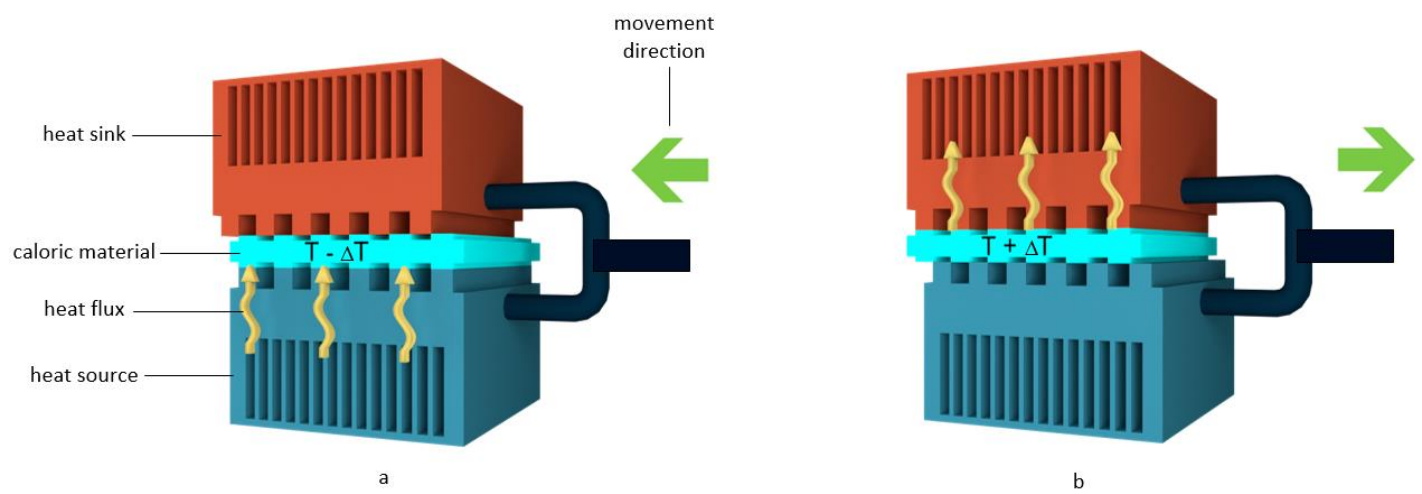

Fig. 17. Example of the self-aligned thermal switch actuated by the stepper motor. The figure has been re-drawn from $[65,66]$.

\subsubsection{Elastocalorics}

Schmidt et al. [68] applied a mechanical thermal switch in their elastocaloric device. A shape-memory alloy, $\mathrm{NiTiCuV}$, was applied as the elastocaloric material. A linear direct-drive motor was used to switch the thermal contact between the NiTiCuV and the heat source/sink. The operating principle is similar to Tsukamoto et al. [40,41], presented in Fig. 5.

Ossmer et al. [69] presented a demonstrator of a elastocaloric heat pump that consisted of TiNiFe shape-memoryalloy bridges. The operation of the device is presented in Fig. 18. When the TiNIFe alloy was loaded, a thermal contact with the heat sink was established. In the unloaded mode, the thermal contact between the alloy and the heat source was established. The highest specific cooling power of $3.3 \mathrm{~W} / \mathrm{g}$ was achieved at an operating frequency of $0.76 \mathrm{~Hz}$. The demonstrator achieved a $9.4 \mathrm{~K}$ temperature span between the heat source and the heat sink for an adiabatic temperature change of $36 \mathrm{~K}$.

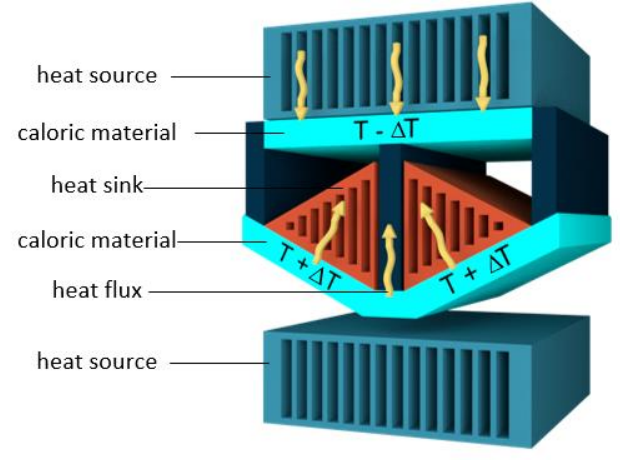

a direction

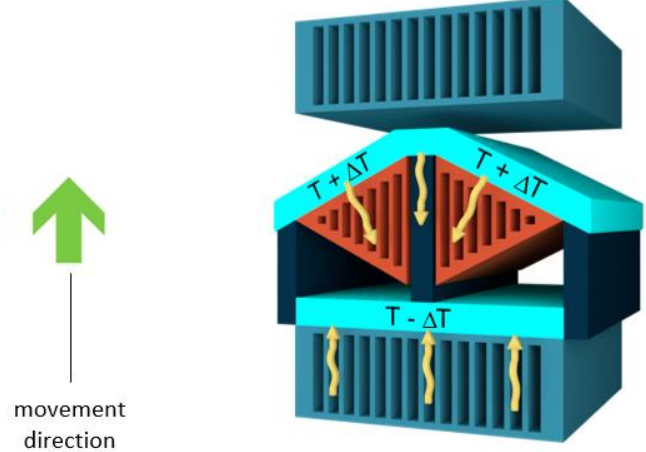

b

Fig. 18. Application of the thermal switch principle in an elastocaloric device. The figure was re-drawn from [69].

\subsection{Thermal diodes in caloric technologies}

\subsubsection{Magnetocaloric}

Maier et al. [70] presented a magnetocaloric refrigeration device with thermal diodes. The device consisted of several compartments containing a porous matrix of the magnetocaloric material and the working fluid (water or ethanol). The operation of the device is similar to a heat pipe, where the working fluid absorbs heat and evaporates 
on one side and then rejects heat and condenses on the other. The compartments were connected to each other by passive check valves. When the magnetocaloric material was magnetized, the working fluid in contact started to evaporate, causing the pressure in the compartment to increase. When the pressure was high enough, the check valve opened and enabled the vapour to flow to the next compartment. When the magnetic field was removed and the magnetocaloric material was demagnetized, the working fluid's pressure decreased, enabling the suction of the gaseous working fluid from the previous compartment. The heat transfer was provided in the uni-direction of the working fluid flow since the check valves prevented any movement in the reverse direction. The authors state that an increase in the temperature span can be obtained by using multiple compartments, thus forming a cascade system.

\subsubsection{Electrocaloric}

Sato [71] proposed the idea of implementing a heat pipe in an electrocaloric cooling device made of $\mathrm{BaTiO}_{3}$ electrocaloric material with a maximum adiabatic temperature change of $0.55 \mathrm{~K}$ and electrodes. The electrocaloric material was on one side fixed to the evaporation area of the heat pipe and on the other side, the condensation area was fixed to the heat sink. When a voltage was applied to the electrodes, the heat transfer from the electrocaloric material caused the acetone to evaporate and transfer heat to the heat sink. When the voltage was removed the heat pipe did not transfer heat to the heat sink; therefore, the heat was transferred only from the heat source to the caloric material. The temperature of the heat sink was kept constant and the device was put in a vacuum chamber. The experiment showed a temperature drop of $0.49 \mathrm{~K}$ at an applied voltage of $300 \mathrm{~V}$ at an operating frequency of 0.1 Hz.

\subsubsection{Elastocaloric}

Bartholome et al. [72] described the application of thermal diodes in elastocalorics. The operating principle is the same as presented in Maier et al. [70]; however, in order to implement the elastocaloric material (Nitinol) another actuation principle was used. The device consisted of many compartments with rods of Nitinol shape-memory alloy. The rods were alternately compressed and stretched, to heat up and cool down due to the elastocaloric effect.

\section{Conclusions and future prospects}

This paper represents a review with guidelines for future research activities in the field of thermal control elements in caloric technologies. The main purpose of the paper is to provide up-to-date information about research activities, as well as to find the answers to two questions: firstly, do thermal control elements perform better than the currently used active caloric regenerator and, secondly, are caloric devices with implemented thermal control elements bringing caloric refrigeration closer to the performance necessary to compete with devices already on the market, e.g., vapour-compression cooling and heat pumping.

The reviewed articles show that in theory the thermal control elements provide features that can overcome the performance limitations of caloric devices based on active caloric regeneration [37,42,46,47]. However, no experimental study was carried out so far that would provide a direct comparison of both principles and for the same operating parameters. On the other hand, the theoretical knowledge gained offers a good basis for guidelines for future theoretical and the missing experimental research activities.

The majority of thermal control elements already implemented in caloric technologies are thermal switches, and the most advanced activities can be found in the field of electrocalorics. Thermal diodes and thermal regulators are more difficult to implement because of the rather small temperature difference caused by the caloric effect. This is due to their known features, such as:

- the wide temperature span required between the two terminals $\left(>>\Delta \mathrm{T}_{\mathrm{ad}}\right)$,

- the absence of a steep anisotropic response in the temperature-dependent thermal resistance,

- the small switching $r_{\text {regulator }}$ or rectification ratio $r_{\text {diode }}$. 
For example, bi-segmented thermal diodes with a linear thermal resistance dependency show theoretical limits of $\mathrm{r}_{\text {diode }} \sim 3$ [73]. However, the research field of thermal diodes and regulators is rapidly developing [74-76], especially in nano-engineering. Bridging the nano-to-macroscopic scales will, however, require major research efforts, and therefore we cannot expect these kinds of thermal control elements to be used efficiently in caloric technologies in the near future.

In contrast to thermal diodes and thermal regulators, thermal switches are not dependent on the temperature. They also enable fast switching times and high ratios. Their drawback is the external energy input required to control the overall thermal resistance. To manage the application of an energy-efficient thermal switch, we should therefore pay special attention to the selection of a method/mechanism that avoids Joule heating, the use of mechanical parts, and provides a good thermal contact with minimal thermal mass.

Table 2 summarizes the existing research results relating to the application and performance of thermal switches in caloric technologies. Some of the reviewed thermal switches could not be characterized properly, as not enough information about their operation is provided in the existing literature. The table does not show the results for some numerical simulations that implemented unrealistic thermal-switch properties (infinite or zero thermal resistance) ([37], [42], [43], [60]).

Table 2: Summary of existing thermal-switch applications in caloric technologies with regard to the actuation principle and the performance.

\begin{tabular}{ccccc} 
NUMERICAL MODELS & \multicolumn{1}{c}{} \\
\hline Type & Switching time & $\mathbf{r}_{\text {switch }}$ & Calorics & Reference \\
\hline Liquid crystals & $\mathrm{ms}$ & 3 & electrocalorics & {$[35]$} \\
Electromechanical actuation & $\mathrm{ms}$ & 1000 & electrocalorics & {$[59]$} \\
Electromechanical actuation & $\mathrm{s}$ & 1000 & electrocalorics & {$[62]$} \\
Mechanically moved & $1 \mathrm{~ms}$ & 100 & electrocalorics & {$[64]$} \\
\hline
\end{tabular}

\section{EXPERIMENTALLY EVALUATED}

\begin{tabular}{ccclc}
\hline Type & Switching time & $\mathbf{r}_{\text {switch }}$ & Calorics & Reference \\
\hline Mechanically actuated & $5.5 \mathrm{~s}$ & 22.5 & magnetocalorics & {$[40,41]$} \\
Magnetic nanofluid & $30 \mathrm{~ms}$ & - & magnetocalorics & {$[49]$} \\
Mechanical-fludic & $3.3 \mathrm{~s}$ & 100 & electrocalorics & {$[54]$} \\
Electrohydrodynamic flow & $40 \mathrm{~s}$ & 4.7 & electrocalorics & {$[56]$} \\
Electrostatically actuated & $30 \mathrm{~ms}$ & - & electrocalorics & {$[61]$} \\
Electromechanical actuation & - & 27 & electrocalorics & {$[63]$} \\
Mechanically moved & $13 \mathrm{~ms}$ & 27 & electrocalorics & {$[65,66]$} \\
\hline
\end{tabular}

While some of the thermal-switch principles show high switching ratios and fast switching times in numerical models, the results of the experiments are less impressive. It is clear that there is still room for further optimization of their performance.

Based on existing knowledge of thermal control elements as well as caloric technologies, we can highlight the targeted features for the efficient application of thermal control elements in caloric energy conversion (Fig. 19). These features specifically address the thermal switches, but the guidelines can also be taken for all other types of thermal control elements.

The targeted features are considering the caloric effect and the specific cooling power of caloric materials. The ratio $\mathrm{r}_{\text {switch }}>10$ follows from the experimental and numerical research described in this review. The minimum switching ratio indirectly proposes the combination of materials that could be used for the thermal switch. A switching time of $20 \mathrm{~ms}$ enables an operating frequency of $25 \mathrm{~Hz}$, if the field change happens instantly, or $12.5 \mathrm{~Hz}$ if the switching time and field change last $20 \mathrm{~ms}$ each. The targeted switching time and the field-change time should enable operating at frequencies higher than $10 \mathrm{~Hz}$, as this is the maximum operating frequency for the active caloric principle. The $4 \mathrm{~K}$ adiabatic temperature change is the approximate change covering all the caloric technologies: very close to the magnetocaloric effect, higher than the electrocaloric effect and lower than the elastocaloric effect. The life 
expectancy of $10^{9}$ cycles is calculated based on operating at $25 \mathrm{~Hz}$ for 5 years. The minimum cooling-power density of $15 \mathrm{~W} / \mathrm{cm}^{2}$ is estimated based on the cooling power of the caloric material (e.g., gadolinium, approx. $7000 \mathrm{~J} / \mathrm{kg}$, which is $0.55 \mathrm{~J}$ for a piece with dimensions of $1 \mathrm{~cm} \times 1 \mathrm{~cm} \times 0.1 \mathrm{~mm}$ ) at an operating frequency of $25 \mathrm{~Hz}$. Because of the low adiabatic temperature change, the temperature span could be increased by building a cascade system. Thermal switches should therefore have the ability to construct a cascade system. As the thermal switches require an external energy input to operate, it is important to pay attention to the energy efficiency of the switching mechanism. The energy efficiency of the thermal switches affects the energy efficiency of the whole device, and therefore an energy efficiency above $85 \%$ is proposed. The ideal thermal switch should not have moving parts, as they cause vibration, noise, reduce the energy efficiency and extend the switching time.

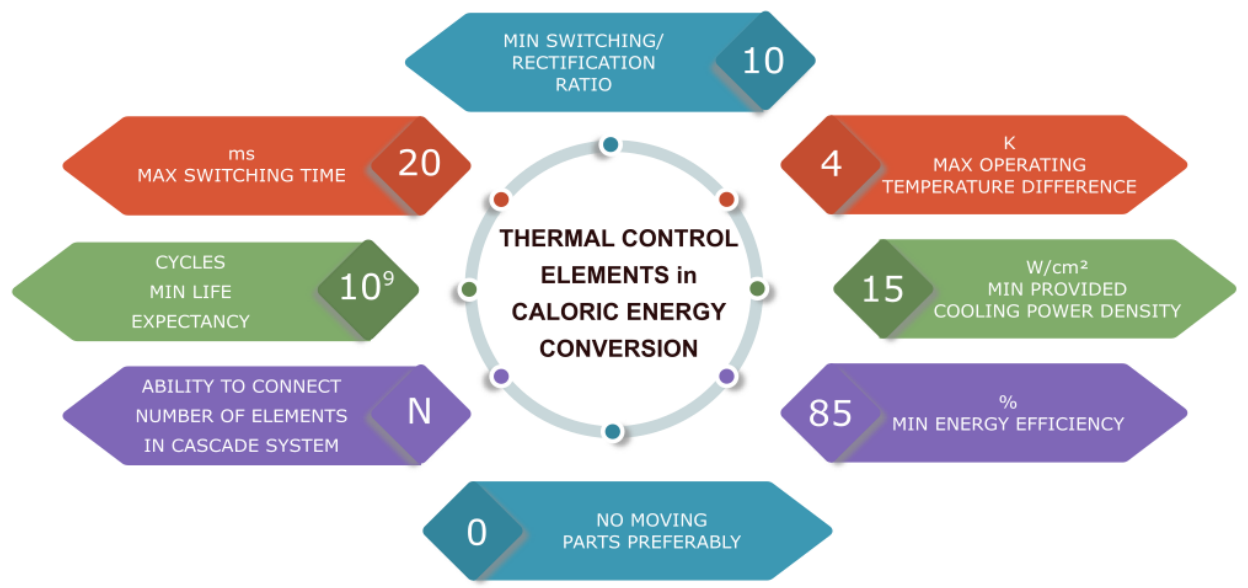

Fig. 19. Targeted features for thermal control elements in caloric energy conversion.

Meeting these technical requirements is not sufficient for the best thermal-control-element candidate to be implemented in the future development of caloric technologies. Additional important parameters are the technology readiness level and the manufacturing complexity, i.e., the cost. Due to the developments in rapid prototyping that can control the heat flux in electronics, MEMS and microfluidics [77,78] there are a variety of possibilities that are becoming available at a relatively low cost.

The most promising principles for the present and near-future applications in caloric energy conversion at room temperature are therefore fluidic thermal switches based on electrical, magnetic and electromechanical actuation. Table 3 presents the most promising concepts for thermal switches that could be implemented in caloric technologies that were already experimentally validated. The concepts are compared in terms of advantages and disadvantages regarding the rectification ratio (- small, + big), the switching time (-slow, + fast) and the requirement for moving parts (+ if not required).

Table 3: Overview of advantages (+) and disadvantages (-) of fluidic thermal-switch candidates for caloric energy conversion.

\begin{tabular}{|c|c|c|c|c|c|}
\hline Type of fluidic thermal switch & Actuation type & $\begin{array}{c}\text { Rectification } \\
\text { ratio }\end{array}$ & $\begin{array}{c}\text { Switching } \\
\text { time }\end{array}$ & $\begin{array}{c}\text { Moving parts } \\
\text { (actuation) }\end{array}$ & References \\
\hline Liquid crystals & electrical & - & + & + & {$[35]$} \\
\hline Dielectric fluid & EHD & - & + & + & {$[56,79]$} \\
\hline Liquid crystals & magnetic & - & - & $+^{*}$ & {$[80]$} \\
\hline Liquid bridges & pressure difference & + & - & - & {$[81]$} \\
\hline Droplet manipulation & electric & + & + & + & {$[82-84]$} \\
\hline Droplet manipulation & magnetic & + & + & $+^{*}$ & {$[85,86]$} \\
\hline (ferro)magnetic (nano)fluids & magnetic & + & + & $+^{*}$ & {$[49,87-89]$} \\
\hline
\end{tabular}

* no moving parts needed in the case of applying an electromagnetic field, but needed in case of permanent magnet 
As can be seen from Table 3, the best combination of existing thermal control elements in calorics is offered by the electrical or magnetic manipulation of droplets and (ferro)magnetic (nano)fluids, which show a high switching ratio, a short switching time and do not require moving parts. From the existing studies, the domain of electrically and magnetically actuated fluidic thermal control elements represents a very promising option.

As can be observed, many of the existing studies require confirmation of numerical results by experiments or the extension of the experimental work, including scaling to different dimensions. Moreover, different geometries and conceptual solutions should be further investigated and demonstrated in caloric prototype devices, with the aim to increase two main parameters: the switching ratio and the switching time. In addition, it is not possible to ignore energy efficiency, which also has to be evaluated. With the intention of improving the performance of a thermal switch, special attention has to be paid to decreasing its thermal mass, reducing its thermal resistance during the ON state and increasing it during the OFF state, avoiding heat generation (e.g., due to the friction, Joule heating) and preventing the formation of undesired thermal bridges.

The domain of solid-state thermal rectification (thermal diodes) $[32,75,90]$ was not listed among the studies, because it was not yet applied to caloric technologies. This domain, as the part of the rapidly developing field of thermal physics, has, because of its static nature, enormous potential to be applied in caloric technologies. Most of the work done in this particular field represents very basic research activities, which first require a good knowledge of phonon transport and manipulation, as well as in nano-engineering. In the future, this type of thermal control element will probably perform better than thermal switches.

Another domain that relates to thermal regulators has proven to be effective in some particular domains, e.g., cryogenics [91], space applications [92], and thermal computing [93]; however, no information on their investigation in caloric technologies at room temperature has been found.

This paper is the first comprehensive review of the existing applications of thermal control elements in caloric technologies at room temperature that offer good potential for an increase in power density and in energy efficiency. We believe the paper will also provide motivation and inspiration to researchers for more research in this particular domain. The knowledge and skills gained from existing studies and future research on thermal control elements in caloric technologies can also serve for other technologies that require the manipulation of a heat flux. The thermal control elements can, for example, be implemented in different applications in cryogenics [91], energy harvesting [94-96], electronics and sensors [97,98], microfluidics [86], biology [99], chemistry [100,101] and even the building sector [102].

\section{Acknowledgements}

The authors acknowledge the financial support of the Slovenian Research Agency for the project Multicaloric cooling J2-9253 and the research core funding No. P2-0223.

\section{References}

[1] She X, Cong L, Nie B, Leng G, Peng H, Chen Y, et al. Energy-efficient and -economic technologies for air conditioning with vapor compression refrigeration: A comprehensive review. Appl Energy 2018;232:157-86. doi:10.1016/j.apenergy.2018.09.067.

[2] Ahamed JU, Saidur R, Masjuki HH. A review on exergy analysis of vapor compression refrigeration system. Renew Sustain Energy Rev 2011;15:1593-600. doi:10.1016/j.rser.2010.11.039.

[3] Domanski PA, Brignoli R, Brown JS, Kazakov AF, McLinden MO. Low-GWP refrigerants for medium and high-pressure applications. Int J Refrig 2017;84:198-209. doi:10.1016/j.ijrefrig.2017.08.019.

[4] Bobbo S, Nicola G Di, Zilio C, Brown JS, Fedele L. Low GWP halocarbon refrigerants: A review of thermophysical properties. Int J Refrig 2018;90:181-201. doi:10.1016/j.ijrefrig.2018.03.027.

[5] Donnellan P, Cronin K, Byrne E. Recycling waste heat energy using vapour absorption heat transformers: 
A review. Renew Sustain Energy Rev 2015:1290-304. doi:10.1016/j.rser.2014.11.002.

[6] Ayou DS, Bruno JC, Saravanan R, Coronas A. An overview of combined absorption power and cooling cycles. Renew Sustain Energy Rev 2013:728-48. doi:10.1016/j.rser.2012.12.068.

[7] Arshi Banu PS, Sudharsan NM. Review of water based vapour absorption cooling systems using thermodynamic analysis. Renew Sustain Energy Rev 2018:3750-61. doi:10.1016/j.rser.2017.10.092.

[8] Hamdy M, Askalany AA, Harby K, Kora N. An overview on adsorption cooling systems powered by waste heat from internal combustion engine. Renew Sustain Energy Rev 2015;51:1223-34. doi:10.1016/j.rser.2015.07.056.

[9] Inayat A, Mohsin R. District cooling system via renewable energy sources: A review. Renew Sustain Energy Rev 2019:360-73. doi:10.1016/j.rser.2019.03.023.

[10] Shirazi A, Taylor RA, Morrison GL, White SD. Solar-powered absorption chillers: A comprehensive and critical review. Energy Convers Manag 2018:59-81. doi:10.1016/j.enconman.2018.05.091.

[11] Leonzio G. Solar systems integrated with absorption heat pumps and thermal energy storages: state of art. Renew Sustain Energy Rev 2017:492-505. doi:10.1016/j.rser.2016.11.117.

[12] Besagni G, Mereu R, Inzoli F. Ejector refrigeration: A comprehensive review. Renew Sustain Energy Rev 2016. doi:10.1016/j.rser.2015.08.059.

[13] Tashtoush BM, Al-Nimr MA, Khasawneh MA. A comprehensive review of ejector design, performance, and applications. Appl Energy 2019. doi:10.1016/j.apenergy.2019.01.185.

[14] Hamid Elsheikh M, Shnawah DA, Sabri MFM, Said SBM, Haji Hassan M, Ali Bashir MB, et al. A review on thermoelectric renewable energy: Principle parameters that affect their performance. Renew Sustain Energy Rev 2014;30:337-55. doi:10.1016/j.rser.2013.10.027.

[15] Enescu D, Virjoghe EO. A review on thermoelectric cooling parameters and performance. Renew Sustain Energy Rev 2014;38:903-16. doi:10.1016/j.rser.2014.07.045.

[16] Brown JS, Domanski PA. Review of alternative cooling technologies. Appl Therm Eng 2014;64:252-62.

[17] Qian S, Nasuta D, Rhoads A, Wang Y, Geng Y, Hwang Y, et al. Not-in-kind cooling technologies: A quantitative comparison of refrigerants and system performance. Int J Refrig 2016;62:177-92. doi:10.1016/j.ijrefrig.2015.10.019.

[18] Goetzler W, Zogg R, Young J, Johnson C. Alternatives to Vapor Compression HVAC Technology. ASHRAE J 2014:12-23.

[19] Kitanovski A, Tušek J, Tomc U, Plaznik U, Ožbolt M, Poredoš A. Magnetocaloric Energy Conversion. Switzerland: Springer; 2015.

[20] Franco V, Blázquez JS, Ipus JJ, Law JY, Moreno-Ramírez LM, Conde A. Magnetocaloric effect: From materials research to refrigeration devices. Prog Mater Sci 2018;93:112-232. doi:10.1016/j.pmatsci.2017.10.005.

[21] Kitanovski A, Plaznik U, Tomc U, Poredoš A. Present and future caloric refrigeration and heat-pump technologies. Int J Refrig 2015;57:288-98. doi:10.1016/j.ijrefrig.2015.06.008.

[22] Shi J, Han D, Li Z, Yang L, Lu S-G, Zhong Z, et al. Electrocaloric Cooling Materials and Devices for Zero-Global-Warming-Potential, High-Efficiency Refrigeration. Joule 2019;3:1200-25. doi:10.1016/j.joule.2019.03.021.

[23] Ožbolt M, Kitanovski A, Tušek J, Poredoš A. Electrocaloric refrigeration: Thermodynamics, state of the art and future perspectives. Int J Refrig 2014;40:174-88. doi:10.1016/j.ijrefrig.2013.11.007.

[24] Aprea C, Greco A, Maiorino A, Masselli C. Electrocaloric refrigeration: an innovative, emerging, ecofriendly refrigeration technique. J Phys Conf Ser 2017;796. doi:10.1088/1742-6596/755/1/011001.

[25] Orhan E, Paridah M., Moradbak A, Mohamed A., Owolabi F abdulwahab taiwo, Asniza M, et al. Refrigeration. Rijeka, Croatia: Intech; 2016. doi:10.5772/57353.

[26] Bruederlin AF, Bumke L, Ossmer H, Chluba C, Quandt E, Kohl M. Elastocaloric Cooling on the Miniature scale: A Review on Materials and Engineering of Devices. Energy Technol 2018;6. doi:10.1002/ente.201800137.

[27] Qian S, Geng Y, Wang Y, Ling J, Hwang Y, Radermacher R, et al. A review of elastocaloric cooling: Materials, cycles and system integrations. Int J Refrig 2016;64:1-19. doi:10.1016/j.ijrefrig.2015.12.001.

[28] Qian S, Yu J, Yan G. A review of regenerative heat exchange methods for various cooling technologies. Renew Sustain Energy Rev 2017;69:535-50. doi:10.1016/j.rser.2016.11.180.

[29] Barclay JA, Steyert WA. Active Magnetic Regenerator. US4332135, 1981.

[30] Wehmeyer G, Yabuki T, Monachon C, Wu J, Dames C. Thermal diodes, regulators, and switches: Physical mechanisms and potential applications. Appl Phys Rev 2017;4. doi:10.1063/1.5001072. 
[31] Garcia-Garcia KI, Alvarez-Quintana J. Thermal rectification assisted by lattice transitions. Int J Therm Sci 2014;81:76-83. doi:10.1016/j.ijthermalsci.2014.03.004.

[32] Roberts NA, Walker DG. A review of thermal rectification observations and models in solid materials. Int J Therm Sci 2011;50:648-62. doi:10.1016/j.ijthermalsci.2010.12.004.

[33] Basiulis A, Beach R, Berry R, Verdes R. Solid-state electrocalric cooling system and method. US4757688, 1988. doi:US005485919A.

[34] Mathur N, Mishchenko A. Solid state electrocaloric cooling revices and methods. WO/2006/056809, 2006.

[35] Epstein RI, Malloy KJ. Electrocaloric devices based on thin-film heat switches. J Appl Phys 2009;106:18. doi:10.1117/12.2004009.

[36] Kitanovski A, Egolf PW. Innovative ideas for future research on magnetocaloric technologies. Int J Refrig 2010;33:449-64. doi:10.1016/j.ijrefrig.2009.11.005.

[37] Tasaki Y, Bahl CRH, Nielsen KK, Olsen UL, Takahashi H, Engelbrecht K. Modeling of in-vehicle magnetic refrigeration. Int J Refrig 2013;37:194-200. doi:10.1016/j.ijrefrig.2013.09.013.

[38] Monfared B. Simulation of solid-state magnetocaloric refrigeration systems with Peltier elements as thermal diodes. Int J Refrig 2017;74:322-30. doi:10.1016/j.ijrefrig.2016.11.007.

[39] Hess T, Maier LM, Corhan P, SchäferWelsen O, Wöllenstein J, Bartholomé K. Modelling cascaded caloric refrigeration systems that are based on thermal diodes or switches. Int J Refrig 2019;103:215-22. doi:10.1016/j.ijrefrig.2019.04.013.

[40] Tsukamoto T, Esashi M, Tanaka S. Magnetocaloric cooling of a thermally-isolated microstructure. J Micromechanics Microengineering 2012;22. doi:10.1088/0960-1317/22/9/094008.

[41] Tsukamoto T, Esashi M, Tanaka S. A micro thermal switch with a stiffness-enhanced thermal isolation structure. J Micromechanics Microengineering 2011;21. doi:10.1088/0960-1317/21/10/104008.

[42] Olsen UL, Bahl CRH, Engelbrecht K, Nielsen KK, Tasaki Y, Takahashi H. Modeling of in-vehicle magnetic refrigeration. Int J Refrig 2014;37:194-200. doi:10.1016/j.ijrefrig.2013.09.013.

[43] Silva DJ, Bordalo BD, Pereira AM, Ventura J, Araújo JP. Solid state magnetic refrigerator. Appl Energy 2012;93:570-4. doi:10.1016/j.apenergy.2011.12.002.

[44] Silva DJ, Ventura J, Araújo JP, Pereira AM. Maximizing the temperature span of a solid state active magnetic regenerative refrigerator. Appl Energy 2014;113:1149-54. doi:10.1016/j.apenergy.2013.08.070.

[45] Tomc U, Tušek J, Kitanovski A, Poredoš A. A new magnetocaloric refrigeration principle with solid-state thermoelectric thermal diodes. Appl Therm Eng 2013;58:1-10.

doi:10.1016/j.applthermaleng.2013.03.063.

[46] Tomc U, Tušek J, Kitanovski A, Poredoš A. A numerical comparison of a parallel-plate AMR and a magnetocaloric device with embodied micro thermoelectric thermal diodes. Int J Refrig 2014;37:185-93. doi:10.1016/j.ijrefrig.2013.07.003.

[47] Egolf PW, Gravier L, Francfort T, Pawlowski AG, Courret G, Croci M. High-frequency magnetocaloric modules with heat gates operating with the Peltier effect. Int J Refrig 2014;37:176-84.

doi:10.1016/j.ijrefrig.2013.09.028.

[48] de Vries W, van der Meer TH. Application of Peltier thermal diodes in a magnetocaloric heat pump. Appl Therm Eng 2017;111:377-86. doi:10.1016/j.applthermaleng.2016.09.103.

[49] Puga JB, Bordalo BD, Silva DJ, Dias MM, Belo JH, Araújo JP, et al. Novel thermal switch based on magnetic nanofluids with remote activation. Nano Energy 2017;31:278-85.

[50] Wu J, Lu B, Liu C, He J. A novel cascade micro-unit regeneration cycle for solid state magnetic refrigeration. Appl Therm Eng 2018. doi:10.1016/j.applthermaleng.2018.03.109.

[51] Lu B, Wu J, He J, Huang J. Heat transfer optimization of a fully solid state micro-unit regeneration magnetic refrigerator. Int J Refrig 2019;98:42-50. doi:10.1016/j.ijrefrig.2018.11.004.

[52] Rondelez F, Urbach W, Hervet H. Origin of Thermal Conductivity Anisotropy in Liquid Crystalline Phases. Am Phys Soc 1978;41:1058-62.

[53] Khodayari A, Mohammadi S. Solid-state cooling line based on the electrocaloric effect. IEEE Trans Ultrason Ferroelectr Freq Control 2011;58:503-8. doi:10.1109/TUFFC.2011.1834.

[54] Jia Y, Sungtaek Ju Y. A solid-state refrigerator based on the electrocaloric effect. Appl Phys Lett 2012;100. doi:10.1063/1.4729038.

[55] Chukka R, Vandrangi S, Shannigrahi S, Chen L. An electrocaloric device demonstrator for solid-state cooling. Epl 2013;103. doi:10.1209/0295-5075/103/47011.

[56] Hehlen MP, Mueller AH, Weisse-Bernstein NR, Epstein RI. Electrocaloric refrigerator using 
electrohydrodynamic flows in dielectric fluids. Laser Refrig Solids VI 2013;8638.

doi:10.1117/12.2004009.

[57] Gu H, Qian XS, Ye HJ, Zhang QM. An electrocaloric refrigerator without external regenerator. Appl Phys Lett 2014;105:1-5. doi:10.1063/1.4898812.

[58] Gu H, Qian X, Li X, Craven B, Zhu W, Cheng A, et al. A chip scale electrocaloric effect based cooling device. Appl Phys Lett 2013;102:2-6. doi:10.1063/1.4799283.

[59] Ju YS. Solid-State Refrigeration Based on the Electrocaloric Effect for Electronics Cooling. J Electron Packag 2010;132:041004. doi:10.1115/1.4002896.

[60] Bradeško A, Juričić D, Santo Zarnik M, Malič B, Kutnjak Z, Rojac T. Coupling of the electrocaloric and electromechanical effects for solid-state refrigeration. Appl Phys Lett 2016;109. doi:10.1063/1.4964124.

[61] Ma R, Zhang Z, Tong K, Huber D, Kornbluh R, Ju YS, et al. Highly efficient electrocaloric cooling with electrostatic actuation. Science (80- ) 2017;357:1130-4. doi:10.1126/science.aan5980.

[62] Almanza M, Depreux L, Parrain F, Lobue M. Electrostatically actuated thermal switch device for caloric film. Appl Phys Lett 2018;112. doi:10.1063/1.5009618.

[63] Smullin SJ, Wang Y, Schwartz DE. System optimization of a heat-switch-based electrocaloric heat pump System optimization of a heat-switch-based electrocaloric heat pump 2015;093903:0-4.

doi:10.1063/1.4928716.

[64] Hirasawa S, Kawanami T, Shirai K. Efficient Cooling System Using Electrocaloric Effect. J Electron Cool Therm Control 2016;06:78-87. doi:10.4236/jectc.2016.62007.

[65] Wang YD, Smullin SJ, Sheridan MJ, Wang Q, Eldershaw C, Schwartz DE, et al. A heat-switch-based electrocaloric cooler. Appl Phys Lett 2015;107. doi:10.1063/1.4932164.

[66] Wang Y, Schwartz DE, Smullin SJ, Wang Q, Sheridan MJ. Silicon Heat Switches for Electrocaloric Cooling. J Microelectromechanical Syst 2017;26:580-7. doi:10.1109/JMEMS.2017.2676704.

[67] Wang Y, Schwartz D, Kalb J, Lee J. A self-regenerating electrocaloric cooler. Proc. Thermag VIII Int. Conf. Caloric Cool., Darmstadt: IIR; 2018, p. 132-6. doi:10.18462/iir.

[68] Schmidt M, Ullrich J, Wieczorek A, Frenzel J, Schütze A, Eggeler G, et al. Thermal Stabilization of NiTiCuV Shape Memory Alloys : Observations During Elastocaloric Training platform. Shape Mem Superelasticity Adv Sci Technol 2015:132-41. doi:10.1007/s40830-015-0021-4.

[69] Ossmer H, Wendler F, Gueltig M, Lambrecht F, Miyazaki S, Kohl M. Energy-efficient miniature-scale heat pumping based on shape memory alloys. Smart Mater Struct 2016;25. doi:10.1088/09641726/25/8/085037.

[70] Maier LM, Hess T, Schaefer-Wiesen O, Woellenstein J, Bartholomé K. Towards high cycle frequencies for magnetocaloric cooling systems - a proof of principle. Thermag VIII - Int. Conf. Caloric Cool. Abstr. B., Darmstadt, Germany: IIR; 2018, p. 107.

[71] Sato W. Imece2013-62258 a Study of a New Cooling Device Based on the Electrocaloric 2014:1-6.

[72] Bartholome K, Fitger A, Winkler M, Schaefer-Welsen O. An elastocaloric cooling system based on latent heat transfer. Thermag VIII - Int. Conf. Caloric Cool. Abstr. B., Darmstadt, Germany: IIR; 2018, p. 348.

[73] Shih TM, Gao Z, Guo Z, Merlitz H, Pagni PJ, Chen Z. Maximal rectification ratios for idealized bisegment thermal rectifiers. Sci Rep 2015;5:1-11.

[74] Boreyko JB, Zhao Y, Chen CH. Planar jumping-drop thermal diodes. Appl Phys Lett 2011;99:2012-5. doi:10.1063/1.3666818.

[75] Wang H, Hu S, Takahashi K, Zhang X, Takamatsu H, Chen J. Experimental study of thermal rectification in suspended monolayer graphene. Nat Commun 2017;8:1-8. doi:10.1038/ncomms15843.

[76] Chen R, Cui Y, Tian H, Yao R, Liu Z, Shu Y, et al. Controllable Thermal Rectification Realized in Binary Phase Change Composites. Sci Rep 2015;5:1-8. doi:10.1038/srep08884.

[77] Paredes J, Fink KD, Novak R, Liepmann D. Self-anchoring nickel microelectrodes for rapid fabrication of functional thermoplastic microfluidic prototypes. Sensors Actuators, B Chem 2015;216:263-70. doi:10.1016/j.snb.2015.04.041.

[78] Morbioli GG, Speller NC, Cato ME, Cantrell TP, Stockton AM. Rapid and Low-Cost Development of Microfluidic Devices Using Wax Printing and Microwave Treatment. Sensors Actuators B Chem 2019;284. doi:10.1016/j.snb.2018.12.053.

[79] Laohalertdecha S, Naphon P, Wongwises S. A review of electrohydrodynamic enhancement of heat transfer. Renew Sustain Energy Rev 2007;11:858-76. doi:10.1016/j.rser.2005.07.002.

[80] Shin J, Kang M, Tsai T, Leal C, Braun P V., Cahill DG. Thermally Functional Liquid Crystal Networks by Magnetic Field Driven Molecular Orientation. ACS Macro Lett 2016;5:955-60. 
doi:10.1021/acsmacrolett.6b00475.

[81] Jeong SH, Nakayama W, Lee SK. Experimental investigation of a heat switch based on the precise regulation of a liquid bridge. Appl Therm Eng 2012;39:151-6. doi:10.1016/j.applthermaleng.2012.01.050.

[82] Cha G, Kim CJ, Ju YS. Thermal conductance switching based on the actuation of liquid droplets through the electrowetting on dielectric (EWOD) phenomenon. Appl Therm Eng 2016;98:189-95.

[83] Gong J, Cha G, Ju YS, Kim CJ. Thermal switches based on coplanar EWOD for satellite thermal control. Proc. IEEE Int. Conf. Micro Electro Mech. Syst., Tucson, USA: MEMS; 2008, p. 848-51.

[84] Yang T, Kwon B, Weisensee PB, Kang JG, Li X, Braun P, et al. Millimeter-scale liquid metal droplet thermal switch. Appl Phys Lett 2018;112. doi:10.1063/1.5013623.

[85] Park Y, Jeon J, Chung SK. Three-dimensional (3D) magnetic droplet manipulation for biomedical applications. Proc IEEE Int Conf Micro Electro Mech Syst 2018;2018-Janua:1283-5. doi:10.1109/MEMSYS.2018.8346799.

[86] Zhang Y, Nguyen NT. Magnetic digital microfluidics - a review. Lab Chip 2017;17:994-1008. doi:10.1039/c7lc00025a.

[87] Cha G, Ju YS, Ahuŕ LA, Wereley NM. Experimental characterization of thermal conductance switching in magnetorheological fluids. J Appl Phys 2010;107:9-12. doi:10.1063/1.3350906.

[88] Seshadri I, Gardner A, Mehta RJ, Swartwout R, Keblinski P, Borca-Tasciuc T, et al. Gating heat transport by manipulating convection in a magnetic nanofluid. Appl Phys Lett 2013;102. doi:10.1063/1.4805070.

[89] Rodrigues C, Dias MM, Martins L, Silva DJ, Araújo JP, Oliveira JCRE, et al. A magnetically-activated thermal switch without moving parts. Energy Convers Manag 2019;197:111881. doi:10.1016/j.enconman.2019.111881.

[90] Maldovan M. Sound and heat revolutions in phononics. Nature 2013;503:209-17. doi:10.1038/nature12608.

[91] Shu QS, Demko JA, Fesmire JE. Heat switch technology for cryogenic thermal management. IOP Conf Ser Mater Sci Eng 2017;278. doi:10.1088/1757-899X/278/1/012133.

[92] Ogden S, Klintberg L, Thornell G, Hjort K, Bodén R. Review on miniaturized paraffin phase change actuators, valves, and pumps. Microfluid Nanofluidics 2014;17:53-71. doi:10.1007/s10404-013-1289-3.

[93] Elzouka M, Ndao S. High Temperature Near-Field NanoThermoMechanical Rectification. Sci Rep 2017;7:1-8. doi:10.1038/srep44901.

[94] Cho JH, Weiss LW, Richards CD, Bahr DF, Richards RF. Power production by a dynamic micro heat engine with an integrated thermal switch. J Micromechanics Microengineering 2007;17. doi:10.1088/0960-1317/17/9/S02.

[95] Bardaweel HK, Anderson MJ, Richards RF, Richards CD. Optimization of the dynamic and thermal performance of a resonant micro heat engine. J Micromechanics Microengineering 2008;18. doi:10.1088/0960-1317/18/10/104014.

[96] Cha G, Ju YS. Pyroelectric energy harvesting using liquid-based switchable thermal interfaces. Sensors Actuators, A Phys 2013;189:100-7.

[97] Geng X, Patel P, Narain A, Meng DD. A self-adaptive thermal switch array for rapid temperature stabilization under various thermal power inputs. J Micromechanics Microengineering 2011;21. doi:10.1088/0960-1317/21/8/085018.

[98] Wang S, Cottrill AL, Kunai Y, Toland AR, Liu P, Wang WJ, et al. Microscale solid-state thermal diodes enabling ambient temperature thermal circuits for energy applications. Phys Chem Chem Phys 2017;19:13172-81. doi:10.1039/c7cp02445b.

[99] Miño-Galaz GA. Allosteric communication pathways and thermal rectification in pdz-2 protein: A computational study. J Phys Chem B 2015;119:6179-89. doi:10.1021/acs.jpcb.5b02228.

[100] Craven GT, He D, Nitzan A. Electron-Transfer-Induced Thermal and Thermoelectric Rectification. Phys Rev Lett 2018;121:247704. doi:10.1103/PhysRevLett.121.247704.

[101] Medrano Sandonas L, Gutierrez R, Dianat A, Cuniberti G. Engineering thermal rectification in MoS2 nanoribbons: a non-equilibrium molecular dynamics study. RSC Adv 2015;5:54345-51. doi:10.1039/c5ra05733g.

[102] Chun W, Ko YJ, Lee HJ, Han H, Kim JT, Chen K. Effects of working fluids on the performance of a bidirectional thermodiode for solar energy utilization in buildings. Sol Energy 2009;83:409-19. doi:10.1016/j.solener.2008.09.001. 